\title{
Transit technology investment and selection under urban population volatility: A real option perspective
}

\author{
Zhi-Chun Li ${ }^{\text {a, }}$, Qian-Wen Guo ${ }^{a}$, William H. K. Lam ${ }^{\text {b,c }}$, S. C. Wong ${ }^{\mathrm{d}}$ \\ ${ }^{a}$ School of Management, Huazhong University of Science and Technology, Wuhan 430074, China \\ ${ }^{\mathrm{b}}$ Department of Civil and Environmental Engineering, The Hong Kong Polytechnic University, Kowloon, \\ Hong Kong, China \\ ${ }^{\mathrm{c}}$ School of Traffic \& Transportation, Beijing Jiaotong University, Beijing 100044, China \\ ${ }^{\mathrm{d}}$ Department of Civil Engineering, The University of Hong Kong, Pokfulam Road, Hong Kong, China
}

\begin{abstract}
This paper addresses transit technology investment issues under urban population volatility using a real option approach. Two important problems are investigated: which transit technology should be selected and when should it be introduced. A real option model is proposed to incorporate explicitly the effects of transit technology investment on urban spatial structure in terms of households' residential location choices and housing market. The trigger population thresholds for investing in a transit technology project and for shifting from a transit technology to another are explored analytically. Comparative static analyses of the urban system and transit technology investment are also carried out. It was found that (i) transit technology investment can induce urban sprawl; (ii) ignoring the effects of transit technology investment on urban spatial equilibrium can lead to a late investment; and (iii) there is a significant difference in the trigger population thresholds for transit technology shift estimated by the net present value approach and the real option approach.
\end{abstract}

Keywords: Transit technology investment and selection; population volatility; real option approach; net present value approach; comparative static analysis; urban spatial equilibrium.

\footnotetext{
${ }^{*}$ Corresponding author. Tel.: +86-27-8754-6073; Fax: +86-27-8755-6437.

E-mail addresses: smzcli@hust.edu.cn (Z.-C. Li), qianwenguo@hust.edu.cn (Q.-W. Guo), william.lam@polyu.edu.hk (W.H.K. Lam), hhecwsc@hkucc.hku.hk (S.C. Wong).
} 


\section{Introduction}

To respond to growing traffic congestion problems, the Chinese government has launched a number of public transportation infrastructure investment projects in recent years. These projects include constructing metro, light rapid transit (LRT), and bus rapid transit (BRT) lines. For instance, a recent statistical report by Liu et al. (2015) showed that by the end of 2014, 83 metro lines with a total length of over $2500 \mathrm{~km}$ had been constructed in 22 metropolitan cities in mainland China, and seven cities had built LRT systems with a total length of over $300 \mathrm{~km}$. The China BRT database (2014) showed that so far, 19 cities in mainland China had already introduced BRT systems with a total length of about $1500 \mathrm{~km}$.

These mass public transportation modes can accommodate a large number of passengers, but require huge investment costs. For example, the capital cost of the Shanghai Metro Line 2 was about RMB600 million per kilometer (RMB is the Chinese currency "Renminbi". US\$1 approximates RMB6.2 as of January 1, 2015) and the Guangzhou BRT Line located on Zhongshan Road cost about RMB50 million per kilometer. Each type of transit technologies has its advantages and disadvantages. For instance, a metro system can carry more passengers at a faster operating speed, but needs higher capital and operating costs than a bus service. BRT is regarded as a high-quality, cost-effective bus-based transit mode. BRT systems use buses to provide faster and more efficient services than an ordinary bus line. These systems combine the speed, reliability, and amenities of rail transit with the flexibility of bus transit. The investment cost of a BRT system is much lower than that of a metro system with the same length. However, the speed and capacity of a BRT system are low, making it difficult to satisfy a high level of passenger demand, particularly in densely populated urban areas. LRT systems are above-ground rail transit systems. They have lower speed and capacity than metros but higher than BRT systems. Their capital cost is between that of a metro and of a BRT system. The trade-off between the operating speed and capacity and the investment cost poses an important question. Which transit technology should an authority introduce so as to improve the efficiency of urban transportation system?

In addition, the feasibility of a transit investment project depends heavily on the urban population size, which directly governs the level of passenger demand for transit services. However, the future population size for a city is uncertain. In particular, with the rapid 
urbanization, a large amount of rural inhabitants in China migrate to urban areas, leading to a large-scale migrant population. It has been reported that China is currently experiencing the largest population migration in the human history, causing a big variation in the urban population size. An investment made too early may cause a low level of travel demand due to a small population size and thus revenue shortfalls and low efficiency, whereas an investment made too late may result in large social costs (such as increasing congestion and pollution) due to leaving demand unmet for too long. This raises another intriguing and important question. When is the most appropriate time for an authority to introduce a new transit technology in a fast-growing city with future population volatility?

In the literature, there are some studies on the transit technology selection and investment timing problems. For instance, several studies have compared the costs or operating efficiencies of selecting different transit technologies, including metro, LRT, and BRT systems (e.g., see Allport, 1981; Stutsman, 2002; Bruun, 2005; Tirachini et al., 2010a). Parajuli and Wirasinghe (2001) developed a multi-attribute decision model to address the transit technology selection problem based on a field survey and an empirical statistical approach. Tirachini et al. (2010b) presented a social welfare and a private profit maximization model to compare the investment benefits of different transit technologies on a linear transportation corridor. Chen et al. (2015) proposed a static (i.e., steady-state), deterministic model to address the transit technology selection problem. In their model, travel demand was assumed to be time-independent and deterministic. Szymanski (1991) compared the timing of infrastructure investment made by a welfare-maximizing public agency and a profit-maximizing private firm. Chu and Polzin (2000) studied the timing rules for major transportation investment using a cost-benefit analysis model. Sivakumaran et al. (2014) explored how the access mode (e.g., walking, bicycle, or feeder bus) affected the choice of transit technology (e.g., heavy rail, BRT, or ordinary bus) for the trunk-line portion of a transit network.

The above-mentioned studies on transit technology investment issues mainly focused on static and deterministic problems. However, the future urban population size and thus the travel demand will stochastically and dynamically fluctuate over time (Saez et al., 2012). This is particularly true for some of the fast-growing cities in China, which have uncertain future population sizes due to large-scale population migration. The return or benefit of a transit technology investment project will therefore also change stochastically and dynamically over 
time. It is therefore necessary to incorporate the dynamics and uncertainty of urban population size over time into transit technology investment models.

These previous related studies have usually used the standard benefit-cost analysis method of net present value (NPV) (Snell, 2011). It has been shown that the traditional NPV approach cannot properly capture management's flexibility to postpone, abandon, or expand an investment opportunity, particularly in an irreversible and uncertain investment environment (Dixit and Pindyck, 1994; Zhao and Tseng, 2003). The real option (RO) valuation approach provides a useful way to capture the value of the flexibility that goes unrecognized in an NPV analysis (McDonald and Siegel, 1986; Trigeorgis, 1996; de Neufville and Scholtes, 2011).

In the past decade, RO theory has attracted considerable attention from transportation researchers. For the convenience of readers, we have summarized in Table 1 some principal contributions of the RO theory to transportation infrastructure investment issues, in terms of the type of transportation infrastructure, decision variables, objective function, investment effects on land use or spatial structure, model solution, and source of uncertainty. This table shows that the previous related studies have mainly focused on the timing issue of transit technology investment, and little attention has been paid to the selection issue of transit technologies. In addition, they usually ignored the effects of transportation infrastructure investment on the urban spatial structure. However, McDonald and Osuji (1995), Bowes and Ihlanfeldt (2001), and Li et al. (2012a, 2013) showed that introducing a new transit line could induce a change in the urban land-use pattern, property values, and housing market in terms of housing rental prices and space, due to improvements in trip accessibility. The change in the urban spatial structure in turn affected the value of the investment project through a change in the travel demand pattern. The effects of transit technology investment projects on households' residential location choices and housing market should therefore be explicitly considered.

In view of the above, this paper addresses transit technology investment and selection issues under urban population volatility based on the RO approach. These issues include which transit technology should be invested in and when. The main contributions of this paper are as follows. First, an RO model is proposed to investigate the transit technology selection and investment timing problems. In the proposed model, the effects of population uncertainty and transit technology investment on the urban spatial structure are considered in terms of 
households' residential location choices and housing market. A comparison between the solutions of the models with and without considering urban spatial/land use equilibrium is made. Second, the trigger population thresholds for investing in a transit technology project and for shifting from a transit technology to another are analytically explored and compared. Third, comparative static analyses of the urban system and the transit technology investment decision are conducted. Sensitivity analyses are also carried out to assess the effects of key model parameters, such as the household income level, population volatility, project construction duration and discount rate, on timely investment decisions about urban transit technology projects. In addition, the loss in project value due to adoption of NPV valuation method but not RO valuation method is also estimated. The results show that transit technology investment can change urban spatial structure, and ignoring the effects of transit technology investment on urban spatial equilibrium can cause a late investment. In addition, there is a big difference in the trigger population thresholds for the transit technology selection estimated by the NPV and RO valuation approaches.

The remainder of the paper is organized as follows. In the next section, housing market equilibrium with transit technology investment is described. Section 3 presents the RO model for transit technology selection and investment timing decisions. In Section 4, two examples are used to illustrate the applications of the proposed model. Finally, the conclusions are given in Section 5, together with recommendations for further studies.

\section{Housing market equilibrium}

In this paper, we assume that a transit investment project consists of three stages (represented by i): before project investment (i.e., before the project exists), during project construction, and after project operations. For presentation purpose, these three stages are indexed by the subscripts 0,1 , and 2, respectively. The public transit modes adopted at stages 0 and 1 are conventional/ordinary public transit modes (e.g., regular bus or minibus), and those at stage 2 are mass public transit modes (e.g., metro, LRT or BRT). In this section, we formulate the housing market equilibrium problem in stage $i$. To facilitate the presentation of the essential ideas without loss of generality, basic model assumptions made in this paper are listed in Table 2. 


\subsection{Households' residential location choices}

We first define the household utility function. Let $x$ be the distance from a household's residential location to the $\mathrm{CBD}$, and $B_{i}$ be the distance from the urban corridor boundary to the CBD (i.e., the city size) in stage i. A Cobb-Douglas utility function (e.g., see Beckmann, 1969, 1974; Solow, 1972, 1973; Li et al., 2012a, 2013) is used:

$$
U_{i}(x)=\alpha \ln z_{i}(x)+\beta \ln g_{i}(x), \quad \alpha, \beta>0, \alpha+\beta=1, x \in\left[0, B_{i}\right], i=0,1,2,
$$

where $U_{i}(x)$ is the utility of the households at location $x$ in stage $i ; z_{i}(x)$ is the consumption of non-housing goods at location $x$ in stage $i$, of which the price is normalized to $1 ; g_{i}(x)$ is the consumption of housing at location $x$ in stage $i$, measured in square meters of floor space; and $\alpha$ and $\beta$ are positive constants.

According to A4, each household within the city chooses a residential location that maximizes its utility subject to budget constraints. The household utility maximization problem can be expressed as

$$
\begin{aligned}
& \max _{z_{i}, g_{i}} U_{i}(x)=\alpha \ln z_{i}(x)+\beta \ln g_{i}(x), \\
& \text { s.t. } \quad z_{i}(x)+p_{i}(x) g_{i}(x)=Y_{i}-\varphi_{i}(x), \quad \forall x \in\left[0, B_{i}\right], i=0,1,2,
\end{aligned}
$$

where $p_{i}(x)$ is the average annual rental price per unit of housing area at location $x$ in stage $i$ and $Y_{i}$ is the average annual household income in stage $i . \varphi_{i}(x)$ is the average annual travel cost from location $x$ to the CBD in stage $i$ and can be estimated by

$$
\varphi_{i}(x)=2 \rho C_{i}(x), \quad \forall x \in\left[0, B_{i}\right], i=0,1,2,
$$

where " 2 " denotes a round trip between the CBD and location $x$, and $\rho$ is the average annual number of trips to the CBD by transit modes per household, based on the average number of daily trips, $\delta$, by transit modes per household (see A5). As an approximation and for illustration purpose, we use $\rho=365 \delta$ in this paper. $C_{i}(x)$ is the (one-way) average travel cost from location $x$ to the CBD. For simplicity, $C_{i}(x)$ is assumed to be a function of travel distance:

$$
C_{i}(x)=\tau \frac{x}{V_{i}}+f_{i}, \quad \forall i=0,1,2,
$$


where $V_{i}$ is the average speed when traveling from location $x$ to the CBD in stage $i, \tau$ is the value of travel time, and $f_{i}$ is the transit fare (where $f_{0}=f_{1}=0$ ). In this paper, we assume that conventional public transit modes (e.g., regular bus, minibus) are adopted at stages 0 and 1, whereas mass public transit modes (e.g., metro, LRT or BRT) are adopted at stage 2 . In addition, the transit project construction may affect the vehicle travel speed due to a decrease in the capacity of transit services. Therefore, $V_{1}<V_{0}<V_{2}$ holds. The values of $V_{2}$ and $f_{2}$ change with the type of transit vehicles. For example, among the metro, LRT and BRT, the metro has the fastest average speed, but the highest fare, whereas the BRT has the slowest average speed, but the lowest fare. The LRT has the middle values for both.

From the first-order optimality conditions of the maximization problem (2)-(3), we obtain

$$
\begin{aligned}
& p_{i}(x)=p_{i}(0)\left(1-\frac{\varphi_{i}(x)}{Y_{i}}\right)^{\frac{1}{\beta}}, \forall i=0,1,2, \\
& g_{i}(x)=\frac{\beta Y_{i}}{p_{i}(0)}\left(1-\frac{\varphi_{i}(x)}{Y_{i}}\right)^{-\frac{\alpha}{\beta}}, \forall i=0,1,2, \text { and } \\
& z_{i}(x)=\alpha\left(Y_{i}-\varphi_{i}(x)\right), \quad \forall i=0,1,2,
\end{aligned}
$$

where $p_{i}(0)$ represents the average rental price of housing in the CBD area, which is determined below. Eqs. (6)-(8) define the equilibrium rental price per unit of housing area, the equilibrium amount of housing floor space per household, and the equilibrium consumption of non-housing goods at location $x$ in stage $i$, respectively.

Substituting Eqs. (6)-(8) into $U_{i}(x)$ in Eq. (1), we obtain the equilibrium household utility:

$$
U_{i}=\alpha \ln \left(\alpha Y_{i}\right)+\beta \ln \left(\frac{\beta Y_{i}}{p_{i}(0)}\right), \forall i=0,1,2 .
$$

Once $p_{i}(0)$ is given, the terms on the right-hand side of Eq. (9) become constants. The households' residential location choice equilibrium state is then reached: all of the households in the linear city have the same utility regardless of their residential locations and housing spaces.

\subsection{Housing production}


We now examine the supply side of the housing market. Let $S_{i}(x)$ be the capital investment per unit of land area at location $x$ in stage $i$, also called the capital investment intensity. It will serve as an indicator to describe the intensity of land development permitted in a particular area. According to A3, the property developers have the following Cobb-Douglas housing production function:

$$
h\left(S_{i}(x)\right)=\mu \cdot\left(S_{i}(x)\right)^{\theta}, \quad 0<\theta<1,
$$

where $h\left(S_{i}(x)\right)$ is the housing supply per unit of land area at location $x$ in stage $i$, and $\mu$ and $\theta$ are positive parameters.

Let $\Lambda_{i}(x)$ be the net profit per unit of land area due to the housing supply at location $x$ in stage $i$, expressed as

$$
\Lambda_{i}(x)=p_{i}(x) h\left(S_{i}(x)\right)-\left(r_{i}(x)+k S_{i}(x)\right), \quad \forall i=0,1,2,
$$

where $r_{i}(x)$ is the rent or value per unit of land area at location $x$ in stage $i$ and $k$ is the price of the capital (i.e., the discount or interest rate). The rental price $p_{i}(x)$ per unit of housing floor area can be determined by Eq. (6). The first term on the right-hand side of Eq. (11) is the total revenue from housing rent. The final two terms are the land rent cost and capital cost, respectively.

According to A3, each property developer in the housing market aims to maximize its net profit by determining the capital investment intensity, expressed as

$$
\max _{S_{i}(x)} \Lambda_{i}(x)=\mu p_{i}(x)\left(S_{i}(x)\right)^{\theta}-\left(r_{i}(x)+k S_{i}(x)\right) .
$$

The first-order optimality condition of maximization problem (12) yields

$$
\frac{\partial \Lambda_{i}(x)}{\partial S_{i}(x)}=\theta \mu p_{i}(x)\left(S_{i}(x)\right)^{\theta-1}-k=0 .
$$

Substituting Eq. (6) into (13) yields

$$
S_{i}(x)=\left(p_{i}(x) \mu \theta k^{-1}\right)^{1 /(1-\theta)}=\left(k^{-1} \mu \theta p_{i}(0)\left(1-\frac{\varphi_{i}(x)}{Y_{i}}\right)^{1 / \beta}\right)^{1 /(1-\theta)}, \forall i=0,1,2 .
$$

Let $n_{i}(x)$ be the household residential density at location $x$ in stage $i$. It is given by

$$
n_{i}(x)=\frac{h\left(S_{i}(x)\right)}{g_{i}(x)}=\frac{1}{\beta Y_{i}}\left(p_{i}(0) \mu\right)^{1 /(1-\theta)}\left(\theta k^{-1}\right)^{\theta /(1-\theta)}\left(1-\frac{\varphi_{i}(x)}{Y_{i}}\right)^{(\alpha+\beta \theta) /(\beta-\beta \theta)} \quad, \quad \forall i=0,1,2 .
$$


Under perfect competition, the property developers earn zero profit. Thus,

$$
r_{i}(x)=\mu p_{i}(x)\left(S_{i}(x)\right)^{\theta}-k S_{i}(x), \quad \forall i=0,1,2 .
$$

Substituting Eqs. (6) and (14) into Eq. (16) yields

$$
r_{i}(x)=k\left(\frac{1}{\theta}-1\right) S_{i}(x)=(1-\theta) \theta^{\theta /(1-\theta)}\left(\mu p_{i}(0)\left(1-\frac{\varphi_{i}(x)}{Y_{i}}\right)^{1 / \beta} k^{-\theta}\right)^{1 /(1-\theta)}, \quad \forall i=0,1,2
$$

Eqs. (14), (15), and (17) define the equilibrium capital investment intensity, household residential density, and land value at any location along a linear urban corridor in stage $i$, respectively. It is evident that given the values of $p_{i}(0), Y_{i}, \mu$, and $\theta$, the capital investment intensity, household residential density, and land value decrease with an increase in either the travel cost or interest rate, and vice versa.

\subsection{Housing demand-supply equilibrium}

The equilibrium of the housing market must satisfy two conditions. First, all of the households fit exactly inside the urban corridor boundary, so that

$$
\int_{0}^{B_{i}} n_{i}(x) d x=N
$$

where $N$ is the total number of households in the city.

Second, the equilibrium rent per unit of land area devoted to housing at the city's edge equals the exogenous agricultural rent or the opportunity cost of the land according to A2:

$$
r_{i}\left(B_{i}\right)=R_{A}
$$

where $R_{A}$ is a constant agricultural rent.

Note that there are two unknowns in Eqs. (18) and (19), $p_{i}(0)$ and $B_{i}$. We can determine their values by solving the two equations jointly.

Proposition 1. Given the agricultural rent $R_{A}$, the rental price of housing in the CBD area $p_{i}(0)$ and the city boundary $B_{i}$ in stage $i$ are given by Eqs. (20) and (21), respectively: 


$$
\begin{aligned}
& p_{i}(0)=\mu^{-1}\left(\frac{k}{\theta}\right)^{\theta}\left(\frac{R_{A}}{1-\theta}\right)^{1-\theta}\left(1-\frac{2 \rho f_{i}}{Y_{i}}\right)^{-1 / \beta}\left(\frac{2 N \rho \tau}{R_{A} V_{i}}+1\right)^{(1-\theta)}, \forall i=0,1,2, \text { and } \\
& B_{i}=\frac{V_{i}}{\tau}\left(\frac{Y_{i}}{2 \rho}-f_{i}\right)\left(1-\left(\frac{2 N \rho \tau}{R_{A} V_{i}}+1\right)^{\beta(\theta-1)}\right), \quad \forall i=0,1,2 .
\end{aligned}
$$

The proof of Proposition 1 is provided in Appendix A. According to Proposition 1, once the housing rental price in the CBD area $p_{i}(0)$ and the city boundary $B_{i}$ are obtained by Eqs. (20) and (21), the equilibrium rent per unit of housing space $p_{i}(x)$, the equilibrium amount of housing space $g_{i}(x)$, the equilibrium household utility $U_{i}$, the equilibrium capital investment intensity $S_{i}(x)$, the equilibrium household residential density $n_{i}(x)$, and the equilibrium land value $r_{i}(x)$ can be determined by Eqs. (6), (7), (9), (14), (15), and (17), respectively.

Proposition 2 provides the comparative static results of the housing rental price in the CBD area $p_{i}(0)$ and the city boundary $B_{i}$.

Proposition 2. Under the assumption $R_{A} V_{2} \square 2 N \rho \tau$, the housing rental price in the city center $p_{i}(0)$ increases with urban population size $N$ and transit fare $f_{i}$, but decreases with household income $Y_{i}$ and transit operating speed $V_{i}$. The city boundary $B_{i}$ increases with household income $Y_{i}$, urban population size $N$, and transit operating speed $V_{i}$, but decreases with transit fare $f_{i}$. The effects of $Y_{i}, N, V_{i}$, and $f_{i}$ on $p_{i}(0)$ and $B_{i}$ are summarized in Table 3.

The proof of Proposition 2 is given in Appendix B. The assumption $R_{A} V_{2} \square 2 N \rho \tau$ generally holds because population size $N$ is usually a large number, particularly in large Chinese cities. Proposition 2 can be explained as follows. (1) If the number of urban population increases, the demand for housing and thus the housing rental price in the city center increases. As a result, some inhabitants would like to move to the city suburbs to enjoy a larger housing space, and the city thus expands. (2) A rise in the transit fare means an increase in the annual household transportation expenses. Some households would thus like to live in the central 
area of the city to reduce their transportation expenses. As a result, the city shrinks and the housing rental price in the city center increases. (3) If the household income level increases, households then have more budget for transportation. Some households would like to reside in the city suburbs and enjoy a larger housing space. Thus, the city expands and the housing rental price in the city center falls. (4) An increase in the transit operating speed means a decrease in travel time, leading some households to move to the city suburbs. Accordingly, the size of the city enlarges and the housing rental price in the city central area decreases.

\section{Model formulation}

\subsection{Cost of transit project}

The annual project cost is incurred by the annual transit line facility cost and annual transit vehicle operating cost. The (annual) transit line facility cost is the sum of the fixed costs (e.g., the line overhead cost) and variable costs (e.g., the land acquisition, line construction, maintenance, and labor costs), proportional to the transit line length, i.e.,

$$
C_{L}=\lambda_{0}+\lambda_{1} L
$$

where $\lambda_{0}$ is the fixed cost, $\lambda_{1}$ is the variable cost per kilometer, and $L$ is the transit line length. For simplicity, the transit line length $L$ is assumed to equal the length of the city under the transit project operations, i.e.,

$$
L=B_{2}
$$

where $B_{2}$ is determined by Eq. (21).

The annual transit operating cost includes the fixed and variable operating costs, which are represented by

$$
C_{O}=\omega_{0}+\omega_{1} \frac{\Theta}{H}
$$

where $\omega_{0}$ is the fixed operating cost, $\omega_{1}$ is the variable operating cost per vehicle, $H$ is the transit headway, $\Theta$ is the average vehicle round journey time, and $\Theta / H$ is the fleet size on the transit line. $\Theta$ can be calculated by

$$
\Theta=\frac{2 L}{V_{2}},
$$


where $V_{2}$ is the average vehicle operating speed after the transit line is put into operation and $L / V_{2}$ is the (one-way) average vehicle journey time.

It should be pointed out that the parameters $\lambda_{0}, \lambda_{1}, \omega_{0}$, and $\omega_{1}$ in Eqs. (22) and (24) depend on the type of transit vehicles. In general, the values of these parameters for a metro are larger than those for an LRT, which are in turn larger than those for a BRT.

\subsection{Transit technology investment timing problem}

The return on or benefit of a transit investment project is the improved accessibility of travel along the urban corridor to the CBD. The derived value from the transit investment project is uncertain due to the uncertainty in the urban population and thus travel demand. To describe the change in the urban population over time, we denote $N(t)$ as the urban population size at time $t$. Suppose that the urban population size follows the geometric Brownian motion in terms of A4. $N(t)$ then satisfies

$$
d N(t)=\eta N(t) d t+\sigma N(t) d w(t),
$$

where $\eta$ is the growth rate of the urban population, $\sigma$ is the volatility rate of the urban population, $d t$ is an infinitesimal time increment, and $d w(t)$ is an increment of a standard Wiener process. For any given period $t, d w(t)$ satisfies the equation $d w(t)=\varepsilon_{t} \sqrt{t}$, where $\varepsilon_{t}$ is a random variable that follows the standard normal distribution with a mean of 0 and a standard deviation of 1 .

Transit infrastructure investment is irreversible due to the huge sunk cost. Studies showed that the traditional NPV method failed to accurately capture the economic value of investment in an uncertain and irreversible environment, whereas the RO approach provided a proper avenue for quantifying the value of management flexibility (McDonald and Siegel, 1986; Dixit and Pindyck, 1994; de Neufville, 2000). An RO refers to the right, but not the obligation, to undertake an action (e.g., deferring, expanding, contracting, or abandoning) at a predetermined cost (the exercise price) for a predetermined period (the life of the option). We use an RO approach to address the investment timing problem for a given transit technology when the urban population size fluctuates over time. 
Determination of the optimal time for introducing a new transit technology is a standard stopping problem. In a low population density city, the passenger demand level is low. Waiting is thus a good strategy when the transit investment cost is high, implying that a "waiting region" is determined. However, in a high population density city, the passenger demand level is high and immediate investment may be a good decision. Accordingly, a "stopping region" is determined. The transit technology investment timing issue aims to determine the population threshold $N^{*}$ that separates the waiting region from the stopping region. When the urban population size $N(t)$ at time $t$ exceeds the population threshold $N^{*}$ (i.e., $N(t)>N^{*}$ ), the transit investment project should be introduced, otherwise it should be deferred.

By the definition of the population threshold $N^{*}$, the authority has no preference between the two assets (i.e., no investment or immediate investment) at $N^{*}$. That is, at $N^{*}$, the values of continuing to wait and immediate investment are equal. We assume that the transit investment project is based on the authority's perspective of expected social welfare maximization (see A1 and A3). The value of continuing to wait is the sum of the expected discounted social welfare without the transit project and the option value of waiting to invest in the transit project. The value of making the investment immediately is the total expected discounted social welfare with the transit investment project, which is the sum of the expected discounted social welfare during the project construction and during the project operation. Let $F(N)$ denote the value of the option of investing in the transit project at population size $N$. Let $S W_{0}(N)$ be the expected discounted social welfare without the transit investment project. Let $S W_{1}(N)$ and $S W_{2}(N)$ be the expected discounted social welfare during the project construction and operation, respectively. At the population threshold $N^{*}$, we have

$$
F\left(N^{*}\right)+S W_{0}\left(N^{*}\right)=S W_{1}\left(N^{*}\right)+S W_{2}\left(N^{*}\right) .
$$

Eq. (27) is the value-matching condition. At $N^{*}$, the expected discounted social welfare without the transit project plus the value of the investment opportunity equals the expected discounted social welfare with the transit project.

We now define the expected discounted social welfare at each investment stage, $S W_{0}(N)$, $S W_{1}(N)$, and $S W_{2}(N)$, as follows. The expected discounted social welfare is the sum of the 
expected discounted consumer surplus and the expected discounted producer surplus (i.e., the expected net profit of the transit investment). When there is no new transit technology investment project, the expected discounted social welfare equals the expected discounted consumer surplus, which depends on the resulting household utility $U_{0}(N(t)) . S W_{0}(N)$ can thus be expressed as

$$
S W_{0}(N)=E_{N}\left[\xi \int_{0}^{+\infty} U_{0}(N(t)) N(t) e^{-k t} d t\right]
$$

where $E_{N}[\cdot]$ is the expectation operator with regard to the population size $N, \xi$ is a parameter used to convert the household utility into equivalent monetary units, $k$ is the riskless interest rate and is assumed to be a known constant across time, and $U_{0}(N(t))$ is the household utility or consumer surplus without the transit investment project, which can be calculated by Eq. (9).

Under the immediate investment strategy, the transit technology investment project includes construction and operation stages. When the transit investment project is under construction, the resultant expected discounted social welfare $S W_{1}(N)$ equals the corresponding expected discounted consumer surplus minus the expected discounted transit line facility cost, represented by

$$
S W_{1}(N)=E_{N}\left[\xi \int_{0}^{\Delta} U_{1}(N(t)) N(t) e^{-k t} d t-\int_{0}^{\Delta} C_{L} e^{-k t} d t\right],
$$

where $\Delta$ is the construction duration of the transit project, which is assumed to be a constant in this paper, and the transit line facility cost $C_{L}$ can be determined by Eq. (22). The transit operating cost is not included in Eq. (29) because the transit facilities are still under construction and thus are not in operation.

When the transit technology investment project is in operation (i.e., interval $[\Delta,+\infty)$ ), the expected discounted social welfare $S W_{2}(N)$ is the difference between the corresponding expected discounted consumer surplus minus the expected discounted transit operating cost:

$$
S W_{2}(N)=E_{N}\left[\xi \int_{\Delta}^{+\infty} U_{2}(N(t)) N(t) e^{-k t} d t-\int_{\Delta}^{+\infty} C_{O} e^{-k t} d t\right],
$$

where the transit operating cost $C_{O}$ can be determined by Eq. (24). 
Substituting Eqs. (28)-(30) into Eq. (27) and carrying out algebraic operations, we obtain

$$
F\left(N^{*}\right)=\Phi\left(N^{*}\right)
$$

where $\Phi(N)$ is given by

$\Phi(N)=E_{N}\left[\int_{0}^{+\infty} \xi\left(U_{1}(\cdot)-U_{0}(\cdot)\right) N(t) e^{-k t} d t+\int_{\Delta}^{+\infty}\left(\xi\left(U_{2}(\cdot)-U_{1}(\cdot)\right) N(t)-C_{O}\right) e^{-k t} d t-\int_{0}^{\Delta} C_{L} e^{-k t} d t\right]$.

It should be noted that $\Phi(N)$ represents the change in the expected discounted social welfare due to the introduction of the transit investment project, also called the investment return/benefit or project value in this paper. Under the mild assumption that $R_{A} V_{2} \square 2 N \rho \tau$, we can derive the analytical expression for $\Phi(N)$ as below. The proof is provided in Appendix C.

Proposition 3. Suppose that $R_{A} V_{2} \square 2 N \rho \tau$ holds, the value of the transit investment project can then be determined by

$$
\begin{aligned}
\Phi(N)= & \xi \beta(1-\theta) \frac{N}{k-\eta} \ln \left(\frac{V_{1}}{V_{0}}\right)+\xi\left[\beta(1-\theta) \ln \left(\frac{V_{2}}{V_{1}}\right)+\ln \left(1-\frac{2 \rho f_{2}}{Y_{2}}\right)\right] \frac{N e^{(\eta-k) \Delta}}{k-\eta} \\
& -\frac{C_{L}\left(1-e^{-k \Delta}\right)}{k}-\frac{C_{O} e^{-k \Delta}}{k} .
\end{aligned}
$$

According to the RO theory (e.g., see Dixit and Pindyck, 1994), the expected return (or value) of the investment opportunity at equilibrium equals its expected rate of capital appreciation over the short time $d t$. This equilibrium condition can be expressed as

$$
k F(N(t)) d t=E_{t}[d F(N(t))] .
$$

Eq. (34) actually represents the Bellman equation for the option value $F(N(t))$. Applying Ito's lemma (e.g., see Dixit and Pindyck, 1994), we can determine the population threshold, $N^{*}$, for introducing a new transit project and the option value function $F(N(t))$ as follows.

Proposition 4. Under the assumption $R_{A} V_{2} \square 2 N \rho \tau$, the trigger population threshold $N^{*}$ and the option value function $F(N(t))$ are, respectively, given by

$$
N^{*}=\frac{b_{1}(k-\eta)\left[C_{L}\left(1-e^{-k \Delta}\right)+C_{O} e^{-k \Delta}\right]}{\xi k\left(b_{1}-1\right)\left(\beta(1-\theta) \ln \left(\frac{V_{1}}{V_{0}}\right)+\left(\beta(1-\theta) \ln \left(\frac{V_{2}}{V_{1}}\right)+\ln \left(1-\frac{2 \rho f_{2}}{Y_{2}}\right)\right) e^{(\eta-k) \Delta}\right)},
$$




$$
F(N(t))=a_{1}(N(t))^{b_{1}}
$$

where

$$
\left\{\begin{array}{l}
b_{1}=\frac{1}{2}-\frac{\eta}{\sigma^{2}}+\sqrt{\left(\frac{\eta}{\sigma^{2}}-\frac{1}{2}\right)^{2}+\frac{2 k}{\sigma^{2}},} \\
a_{1}=\left(\frac{\xi}{b_{1}(k-\eta)}\left(\beta(1-\theta) \ln \left(\frac{V_{1}}{V_{0}}\right)+\left(\beta(1-\theta) \ln \left(\frac{V_{2}}{V_{1}}\right)+\ln \left(1-\frac{2 \rho f_{2}}{Y_{2}}\right)\right) e^{(\eta-k) \Delta}\right)\right)^{b_{1}}\left(\frac{k\left(b_{1}-1\right)}{C_{L}\left(1-e^{-k \Delta}\right)+C_{O} e^{-k \Delta}}\right)^{b_{1}-1} .
\end{array}\right.
$$

The proof of Proposition 4 is provided in Appendix D. We carry out a comparative static analysis of the population threshold $N^{*}$ and obtain the following results.

Proposition 5. $N^{*}$ is positively correlated with the urban population volatility rate $\sigma$, the marginal capital cost of the transit line $\lambda_{1}$, and the marginal operating cost of the transit line $\omega_{1}$, i.e., $\frac{\partial N^{*}}{\partial \sigma}>0, \frac{\partial N^{*}}{\partial \lambda_{1}}>0$, and $\frac{\partial N^{*}}{\partial \omega_{1}}>0$. When the marginal capital cost of the transit line is larger than its marginal operating cost (i.e., $C_{L} \geq C_{O}$ ), $N^{*}$ is positively correlated with the transit project construction duration $\Delta$, i.e., $\frac{\partial N^{*}}{\partial \Delta}>0$.

The proof of Proposition 5 is given in Appendix E. It should be pointed out that the signs of $N^{*}$ with regard to the household income level and the discount rate (i.e., $\frac{\partial N^{*}}{\partial Y_{i}}$ and $\frac{\partial N^{*}}{\partial k}$ ) are difficult to determine analytically. A simulation method is therefore used to ascertain their relationships in the later numerical example.

For comparison purpose, we derive the population threshold of the traditional NPV model as follows. In the NPV approach, a transit project is introduced if and only if the expected discounted social welfare with the transit project just exceeds that without the project, i.e.,

$$
S W_{1}\left(N_{\mathrm{NPV}}^{*}\right)+S W_{2}\left(N_{\mathrm{NPV}}^{*}\right) \geq S W_{0}\left(N_{\mathrm{NPV}}^{*}\right) .
$$

From Eq. (38), the population threshold in the NPV approach is obtained as below: 


$$
N_{\mathrm{NPV}}^{*}=\frac{(k-\eta)\left[C_{L}\left(1-e^{-k \Delta}\right)+C_{O} e^{-k \Delta}\right]}{\xi k\left(\beta(1-\theta) \ln \left(\frac{V_{1}}{V_{0}}\right)+\left(\beta(1-\theta) \ln \left(\frac{V_{2}}{V_{1}}\right)+\ln \left(1-\frac{2 \rho f_{2}}{Y_{2}}\right)\right) e^{(\eta-k) \Delta}\right)} .
$$

Given the model parameters, from Eqs. (35) and (39), we can obtain the relationship between the population thresholds under the RO and NPV approaches as follows:

$$
N^{*}=\frac{b_{1}}{b_{1}-1} N_{\mathrm{NPV}}^{*} .
$$

Eq. (40) implies that the population threshold under the RO approach is always larger than that under the NPV approach, as the RO approach incorporates the value of flexibility through the option to wait and defer investment.

\subsection{Transit technology selection problem}

As assumed in A1, the authority or government makes transit investment decisions in a sequential way, i.e., first deciding which transit technology to choose, and then when to invest. Accordingly, once a transit technology is chosen, the optimal timing (i.e., the trigger population threshold) for a transit technology investment can then be determined by using the method developed in Section 3.2. In this section, we address the transit technology selection problem: given multiple transit technology options, which transit technology is the most appropriate to invest in.

Let us consider multiple alternative transit technologies, such as the metro, LRT, and BRT, which are undergoing rapid developments and applications in some large Chinese cities. For a given urban population size, different transit technologies can bring different investment returns. Following A3, the authority will choose to introduce the transit technology that yields the highest return on the investment. Let $M$ be the set of alternative transit technologies and $m_{1}$ and $m_{2}$ be two transit technology options, where $m_{1}, m_{2} \in M$. Let $\Psi_{m_{1}}(N)$ and $\Psi_{m_{2}}(N)$ be the investment benefits of transit technologies $m_{1}$ and $m_{2}$ under population size $N$, respectively. The definition of $\Psi(\cdot)$ is applicable to different investment valuation methods. Specifically, “ $\Psi(\cdot)=F(\cdot)$ " (see Eq. (36)) implies that an RO valuation method is used, and " $\Psi(\cdot)=\Phi(\cdot)$ " (see Eq. (33)) implies that the NPV method is used. For presentation purpose, we introduce two definitions. 
Definition 1 (A dominant transit technology). Transit technology $m_{1}$ is dominant over technology $m_{2}$ in the region $\left[N^{L}, N^{U}\right]$ if the transit investment benefit function satisfies

$$
\Psi_{m_{1}}(N) \geq \Psi_{m_{2}}(N), \quad N \in\left[N^{L}, N^{U}\right]
$$

where $N^{L}$ and $N^{U}$ are the lower and upper bounds of the dominant region, respectively. When $\left[N^{L}, N^{U}\right]$ is the real number field, it is called wholly dominant.

Definition 2 (Trigger population threshold for transit technology shift). The population size $\bar{N}$ is at the critical (or trigger) level for shifting from transit technology $m_{2}$ to $m_{1}$ if and only if Inequality (41) becomes binding at $\bar{N}$, i.e.,

$$
\Psi_{m_{1}}(\bar{N})=\Psi_{m_{2}}(\bar{N})
$$

The following proposition further reveals the difference of the NPV and RO valuation approaches from the perspective of the transit technology shift.

Proposition 6. (i) Under the NPV approach, there is a critical population size $\bar{N}_{N P V}$ for transit technology shift from $m_{2}$ to $m_{1}$, expressed as

$$
\bar{N}_{N P V}=\frac{(k-\eta)\left[\left(C_{L}^{m_{1}}\left(1-e^{-k \Delta_{m_{1}}}\right)+C_{O}^{m_{1}} e^{-k \Delta_{m_{1}}}\right)-\left(C_{L}^{m_{2}}\left(1-e^{-k \Delta_{m_{2}}}\right)+C_{O}^{m_{2}} e^{-k \Delta_{m_{2}}}\right)\right]}{\xi k\left(\left(\beta(1-\theta) \ln \left(\frac{V_{2}^{m_{1}}}{V_{1}}\right)+\ln \left(1-\frac{2 \rho f_{2}^{m_{1}}}{Y_{2}}\right)\right) e^{(\eta-k) \Delta_{m_{1}}}-\left(\beta(1-\theta) \ln \left(\frac{V_{2}^{m_{2}}}{V_{1}}\right)+\ln \left(1-\frac{2 \rho f_{2}^{m_{2}}}{Y_{2}}\right)\right) e^{(\eta-k) \Delta_{m_{2}}}\right)} \cdot
$$

(ii) Under the RO approach, a transit technology is wholly dominant over the other transit technology in terms of the option value. Specifically, transit technology $m_{1}$ (e.g., metro) wholly dominates technology $m_{2}$ (e.g., LRT) when Inequality (44) holds, and vice versa.

$$
\frac{\beta(1-\theta) \ln \left(\frac{V_{1}}{V_{0}}\right)+\left(\beta(1-\theta) \ln \left(\frac{V_{2}^{m_{1}}}{V_{1}}\right)+\ln \left(1-\frac{2 \rho f_{2}^{m_{1}}}{Y_{2}}\right)\right) e^{(\eta-k) \Delta_{m_{1}}}}{\beta(1-\theta) \ln \left(\frac{V_{1}}{V_{0}}\right)+\left(\beta(1-\theta) \ln \left(\frac{V_{2}^{m_{2}}}{V_{1}}\right)+\ln \left(1-\frac{2 \rho f_{2}^{m_{2}}}{Y_{2}}\right)\right) e^{(\eta-k) \Delta_{m_{2}}}} \geq\left(\frac{C_{L}^{m_{1}}\left(1-e^{-k \Delta_{m_{1}}}\right)+C_{O}^{m_{1}} e^{-k \Delta_{m_{1}}}}{C_{L}^{m_{2}}\left(1-e^{-k \Delta_{m_{2}}}\right)+C_{O}^{m_{2}} e^{-k \Delta_{m_{2}}}}\right)^{\frac{b_{1}-1}{b_{1}}}
$$

Proof. Property (i) with the NPV approach can directly be derived by substituting Eq. (33) into Eq. (42). For Property (ii), when Inequality (44) holds, we can obtain $a_{1}^{m_{1}} \geq a_{1}^{m_{2}}$ by Eq. 
(37), and thus $F_{m_{1}}(N) \geq F_{m_{2}}(N)$ for any $N$ by Eq. (36). According to Definition $1, m_{1}$ wholly dominates $m_{2}$. This completes the proof of this proposition.

Proposition 6 shows that given transit technologies $m_{1}$ and $m_{2}$, for the NPV model, when the population size reaches the critical level of $\bar{N}_{N P V}$, then the transit technology to be adopted should shift from $m_{2}$ to $m_{1}$. However, for the RO model, as long as Inequality (44) is satisfied (this is usually the case), transit technology $m_{1}$ is wholly dominant over transit technology $m_{2}$.

Remark. It can be seen in Eq. (43) that the critical population size $\bar{N}_{N P V}$ relies on such parameters as transit vehicle operating speed $V_{2}$, transit fare $f_{2}$, construction duration of transit line $\Delta$, transit line facility cost $C_{L}$ and transit operating cost $C_{O}$. These parameters describe the intrinsic characteristics of a transit technology and their values may change with the type of transit technologies. Among these parameters, $V_{2}, f_{2}$, and $C_{O}$ are relatively stable. However, $C_{L}$ and $\Delta$ may be significantly affected by the urban environment and site condition in terms of hydro-geological characteristics, and are thus sensitive and varied considerably, particularly for the metro technology. It can easily be shown by Eq. (43) that when $C_{L} \geq C_{O}$ holds for transit technology $m$, the critical population size $\bar{N}_{N P V}$ with the NPV approach satisfies

$$
\frac{\partial \bar{N}_{N P V}}{\partial C_{L}^{m_{1}}}>0, \frac{\partial \bar{N}_{N P V}}{\partial \Delta_{m_{1}}}>0, \frac{\partial \bar{N}_{N P V}}{\partial C_{L}^{m_{2}}}<0 \text {, and } \frac{\partial \bar{N}_{N P V}}{\partial \Delta_{m_{2}}}<0 .
$$

Eq. (45) means that $\bar{N}_{N P V}$ increases with the increase in the values of $C_{L}^{m_{1}}$ and $\Delta_{m_{1}}$ of transit technology $m_{1}$, but decreases with the increase in the values of $C_{L}^{m_{2}}$ and $\Delta_{m_{2}}$ of transit technology $m_{2}$.

Note that $N^{*}$ in Eq. (35) or (39) presents the population threshold for introducing a transit technology. $\bar{N}$ in Eq. (43) defines the trigger population threshold for shifting from one transit technology to another under the NPV approach. The value of $\bar{N}$ may differ from that of $N^{*}$. We thus have the following definition: 
Definition 3. The trigger population threshold $N^{* *}$ for selecting a transit technology from multiple options is defined as the maximum of the population threshold of that transit technology itself $N^{*}$ and the critical population threshold for transit technology shift $\bar{N}$, i.e.,

$$
N^{* *}=\max \left(N^{*}, \bar{N}\right)
$$

Once the population size of a city reaches the trigger population size $N^{* *}$, the new transit technology can then be launched. It should be pointed out that according to Proposition 6(ii) and Eq. (46), under the RO approach, the value of $N^{* *}$ is equal to that of $N^{*}$. However, both may not be equal under the NPV approach.

\section{Model applications}

In this section, two test examples are used to illustrate the applications of the proposed model and the contributions of this study. The first example is intended to reveal the difference in the transit technology investment decisions with and without urban spatial or land use equilibrium consideration. The case without considering the land use equilibrium implies that the urban spatial structure in terms of urban residential distribution, housing rental price and space, and urban size is the same as that before transit technology investment. The effects of a transit technology investment on the urban spatial structure and the effects of the key model parameters (e.g., the project construction duration, discount rate, household income level, and population volatility) on the trigger population threshold for a transit technology investment are also investigated. The second example illustrates the real application of the proposed model in two candidate Chinese cities.

In the following analysis, unless specifically stated otherwise, the input parameters and baseline values used in the model are the same as those shown in Table 4. Three types of transit technologies, the BRT, LRT, and metro, are considered. The input parameters for these technologies are given in Table 5.

\subsection{Example 1: Illustration of model properties}




\subsubsection{Comparison of investment decisions with and without land use integration}

Figs. 1a and b depict the option value curves (in bold line) and the NPV curves (in dotted line) under different transit technology investments with and without incorporating the land use equilibrium, which can be calculated by Eqs. (36) and (33), respectively. In Figs. 1a and b, the intersection point ( $\mathrm{D}$ or $\mathrm{D}^{\prime}$ ) between the option value curve and the NPV curve for a given transit technology represents the population threshold $N^{*}$ of the corresponding transit technology under the RO approach in terms of Eq. (31). The intersection point $\left(\mathrm{G}\right.$ or $\left.\mathrm{G}^{\prime}\right)$ between the NPV curve and the horizontal line represents the population threshold $N_{\mathrm{NPV}}^{*}$ under the NPV approach according to Eq. (39). The intersection point ( $\mathrm{X}$ or $\mathrm{X}^{\prime}$ ) between the NPV curves of different transit technologies represents the critical population size $\bar{N}_{N P V}$ for transit technology shift by Eq. (43). The trigger population threshold $N^{* *}$ for transit technology selection from multiple options is determined by Eq. (46). The population threshold solutions with and without the land use equilibrium consideration under the RO and NPV approaches are shown in Table 6.

Some main insights in Figs. $1 \mathrm{a}$ and $\mathrm{b}$ and Table 6 are summarized as follows. First, the option value curve of the metro is above that of the LRT, which is above that of the BRT. This means that a costlier technology has a higher option value. Specifically, the option value of the metro is the highest, and that of the BRT is the lowest, and that of the LRT is in between. That is, the metro wholly dominates the LRT and the BRT, and the LRT wholly dominates the BRT in terms of the option value, which is consistent with that in Proposition 6(ii). This result favors prior introduction of a costlier technology from the perspective of the option value. As a result, a long wait for investment is needed such that the urban population size grows to the level of the trigger population threshold. In reality, the public cannot see such an option value that will be realized at a future time, and want their tax money to benefit them now as opposed to the future. Therefore, from the public perspective, an "effective" discount rate, which may be much higher than the real discount rate, can be used in a real application. Second, ignoring the effects of the transit technology investment on the land use or urban spatial equilibrium will lead to a late investment due to an underestimation of the investment benefits or returns. We take the RO solution as an example. With the land use equilibrium 
consideration, the trigger population thresholds $N^{*}$ for the metro, LRT, and BRT are 8.20, 6.20, and 4.39 million people, associated with points $D_{3}, D_{2}$, and $D_{1}$ in Fig. 1a, respectively. The corresponding values of $N^{*}$ without the land use equilibrium are 9.50, 6.50, 4.70 million people, which are points $D_{3}^{\prime}, D_{2}^{\prime}$, and $D_{1}^{\prime}$ in Fig. $1 \mathrm{~b}$, respectively. Similar results can be observed for the NPV solution. Third, under the NPV approach, the population threshold solutions for a single transit technology $\left(N^{*}\right)$ and for selecting between multiple transit technology options $\left(N^{* *}\right)$ are different. For example, for the case with land use equilibrium consideration, the NPV solutions $N^{*}$ for the metro and LRT are 5.70 and 4.31 million people (i.e., points $G_{3}$ and $G_{2}$ in Fig. 1a), respectively. However, the corresponding values of $N^{* *}$ are 6.38 and 4.85 million people (i.e., points $X_{3}$ and $X_{2}$ in Fig. 1a), respectively. This result also holds for the case without the land use equilibrium consideration (see Fig. 1b). Fourth, for a given transit technology, the RO approach leads to a higher population threshold $N^{*}$ than the NPV approach, which satisfies Eq. (40). For example, with the land use equilibrium consideration, the population thresholds $N^{*}$ for the metro under the RO and NPV approaches are 8.20 and 5.70 million, for the LRT are 6.20 and 4.31 million, and for the BRT are 4.39 and 3.05 million people, respectively. The NPV approach therefore leads to a premature transit investment decision, which further illustrates the result underlying Eq. (40).

\subsubsection{Effects of transit technology investment project on the urban structure}

Figs. 2a-d display the profiles of the equilibrium household residential density, equilibrium housing rental price, equilibrium housing space per household, and equilibrium capital investment intensity, respectively, for an urban population size of 8.2 million people, which is the RO population threshold for introducing the metro technology (see Fig. 1a or Table 6). Fig. 2 a shows that in contrast with the "doing nothing" scenario (no new transit technology is introduced), introducing a transit technology can cause urban expansion or growth due to the increased accessibility and convenience to the city center. Introducing a metro, LRT, or BRT causes the city to grow by $15.6 \mathrm{~km}, 10.3 \mathrm{~km}$, or $6.3 \mathrm{~km}$, respectively, as shown in Table 7 . The residential density in the urban central area then decreases, whereas that in the city's outskirts increases, compared with the "doing nothing" scenario. The housing rental prices 
and capital investment intensity in the suburbs then increase, whereas those in the urban central area decrease, as shown in Figs. $2 b$ and $d$. As a result of the residential density decrease in the urban central area and the capital investment intensity increase in the suburbs, the housing spaces per household in the urban central area and in the suburbs increase, as shown in Fig. 2c.

Table 7 further summarizes the effects of introducing a transit technology on the equilibrium solution of the urban system when the urban population size is fixed as 8.2 million people. It shows that introducing a transit technology can lead to a decrease in the average urban residential density, average housing rental price, average land value, and average capital investment intensity, but an increase in the average housing space. Of the three technologies, the effects of the metro on the urban system are the greatest, those of the LRT are the second greatest, and those of the BRT are the smallest. Specifically, the introduction of the metro, LRT, or BRT leads to a decrease in the average urban residential density of 238,144 , or 68 households per square meter, in the average housing rental price of RMB1092, RMB542, or RMB120 per square meter, in the average land value of RMB165, RMB101, or RMB29 per square meter, and in the average capital investment intensity of RMB29.3, RMB22.1 or RMB10.0 million per square kilometer, but an increase in the average housing space per household of 10,8 , or 5 square meter per household, respectively.

\subsubsection{Effects of the metro project construction duration and discount rate on the population threshold}

In reality, a metro project construction duration is closely related to the urban geological conditions, whereas the duration of an LRT or BRT project construction is relatively stable. Fig. 3 shows the effects of the metro project construction duration and the discount (or interest) rate on the trigger population threshold. For a given discount rate, the longer the metro project construction duration, the higher the population threshold, and vice versa. A long construction duration implies a high investment opportunity cost, which reduces the attraction of the investment project. Accordingly, it would be better to postpone the investment and wait for the project value to increase with the population growth. On the contrary, for a given metro project construction duration, as the discount rate increases, the population threshold decreases, and vice versa, because a high discount rate means a high project investment cost. Therefore, a wise decision is to invest early at a low discount rate to 
reduce the investment cost.

\subsubsection{Effects of the household income and population volatility on the population threshold}

Fig. 4 plots the change of the population threshold as the household income level and urban population volatility change. It shows that for a given population volatility, the trigger population threshold decreases with an increase in the household income level. A growth in the household income level implies an increase in the budget for transportation and housing consumption, according to Eq. (3). Some inhabitants would therefore like to live in the city suburbs and enjoy a larger housing space. A mass rapid transit mode should thus be introduced earlier to satisfy the inhabitants' needs, leading to a decreasing population threshold. In contrast, for a fixed household income level, as the population volatility increases, the trigger population threshold also increases. This is because an increase in the urban population volatility means an increase in the flexibility (or option) value of the transit investment project (in fact, it is easy to show that $\partial F\left(N^{*}\right) / \partial \sigma>0$ holds in terms of Eq. (36)). Deferring the investment is therefore a better strategy than immediate investment.

\subsection{Example 2: Case studies of two cities in China}

For further illustration purpose, we apply the proposed transit technology investment model to two candidate Chinese cities: Dalian and Changzhou. Dalian is a medium-density city located in Liaoning province, northeastern China. Changzhou is a low-density city located in Jiangsu province, eastern China. Table 8 shows the numbers of residents (which is the sum of the registered permanent residents and the migrant residents) and the per capita income levels of the two candidate cities between 1994 and 2014, according to the China Statistical Yearbooks (NBSC, 1994-2014). The associated annual growth rates of the population sizes and the per capita income levels for these two cities are also shown in Table 8, together with the volatility rates of the population sizes. In order to apply the households' residential location choice model that is proposed in Section 2, the population size and the per capita income level in Table 8 need to be converted to a household level from a personal level. To do so, we assume in this example that each household has three persons (i.e., parents and one child) in terms of the China's one-child policy, and each household makes an average of 3.0 trips to the CBD by transit modes per day, i.e., $\delta=3.0$. We also assume that since 2014, the change in the 
population size over time follows a geometric Brownian motion and the per capita income level grows at the current average annual growth rate (see Table 8). Without loss of generality, we generate three trajectories (or paths) of the urban population size over time for each of the two cities according to the geometric Brownian motion, as indicated on the right-hand side of Fig. 5. The change trajectory of the per capita income level over time (based on the current average annual growth rate) for each city is shown on the right-hand side of Fig. 6.

Figs. $7 \mathrm{a}$ and $\mathrm{b}$ show the change curves of the annual option value and annual NPV when different transit technologies are, respectively, introduced into Dalian and Changzhou and the changes in the future population sizes of these two cities follow the simulated population trajectory 1 (see Fig. 5). Fig. 7a shows that the option value and NPV curves for the LRT intersect at point Q1, which is associated with an investment in 2007 and yields a project value of RMB7.31 billion. The option value and NPV curves for the metro intersect at point Q2 with an investment in 2015, yielding a project value of RMB17.32 billion. Points Q1 and Q2 are the results estimated with the RO approach in terms of Eq. (35). Fig. 7a also shows that the NPV curves for the LRT and metro intersect with the horizontal axis at points Q3 and Q4, respectively, which are the results estimated with the NPV approach. Their corresponding investment timings are 1997 and 2001, respectively. Similarly, Fig. 7b shows that the optimal investment decisions generated with the RO approach for the BRT, LRT, and metro occur at points W1, W2, and W3, with investments in 2003, 2009, and 2020 and project values of RMB2.98, RMB5.67, and RMB23.81 billion, respectively. The optimal investment timings generated with the NPV approach are 1997, 2001, and 2005, which are associated with points W4, W5, and W6, respectively.

Table 9 summarizes the estimated transit technology investment timings with the RO and NPV approaches under the simulated population trajectory 1 for Dalian and Changzhou. It can be seen that the NPV approach induces earlier investments than the RO approach of 14 and 10 years for the metro and LRT for Dalian, and of 15, 8, and 6 years for the metro, LRT, and BRT for Changzhou, respectively.

In addition, from Figs. $7 \mathrm{a}$ and $\mathrm{b}$, one can calculate the total project values accrued from the investment time estimated with the NPV approach to that with the RO approach for the two cities under the simulated population trajectory 1 , as well as the corresponding loss in the project values if the investment occurs at the time estimated with the NPV approach but not 
with the RO approach. According to Fig. 7a, for the metro investment project in Dalian, the total option value and the total NPV accrued from 2001 (i.e., the estimated investment time with the NPV approach) to 2015 (i.e., the estimated investment time with the RO approach) are, respectively, the areas of $Q_{2} Q_{2}^{\prime} Q_{4} Q_{4}^{\prime}$ and $Q_{2} Q_{2}^{\prime} Q_{4}$, causing a loss in the project value equal to the area of $Q_{2} Q_{4} Q_{4}^{\prime}$. If Dalian invests in an LRT project in 1997 but not 2007, a loss in the project value equal to the area of $Q_{1} Q_{3} Q_{3}^{\prime}$ is then incurred. Similarly, the investment timing decisions about metro, LRT and BRT projects in Changzhou under the NPV approach can, respectively, lead to losses in the project values equal to the areas of $W_{3} W_{6} W_{6}^{\prime}, W_{2} W_{5} W_{5}^{\prime}$, and $W_{1} W_{4} W_{4}^{\prime}$, compared with those under the RO approach.

In the foregoing discussions, we have presented the solution of the transit technology investment decision problem under a specific population trajectory (i.e., trajectory 1). Note that different population trajectories could yield different investment value curves and thus different investment decisions for a given valuation approach (RO or NPV approach). Therefore, it is meaningful to calculate the average project value over the simulated population trajectories and the associated average loss for each city concerned, as shown in Table 10. It can be seen in this table that the average option value and the average NPV for the metro investment project in Dalian are, respectively, RMB151.76 billion and RMB107.13 billion, causing an average loss of RMB44.63 billion. For the LRT investment project in Dalian, the NPV approach will incur an average loss of RMB19.11 billion compared to the RO approach. In addition, the investment decisions given by the NPV approach for metro, LRT and BRT projects in Changzhou can, respectively, yield average losses of RMB74.20 billion, RMB11.87 billion, and RMB4.85 billion, in contrast to those given by the RO approach. These results further illustrate the bias of the NPV approach in determining timely investment decisions for transit technology.

\section{Conclusion and further studies}

In this paper, an RO model was proposed to address transit technology investment and selection problems with consideration of uncertainty in urban population size. The effects of a transit technology investment on the urban system in terms of households' residential location choices and housing market were endogenously incorporated in the proposed model. The 
properties of the proposed model were explored analytically, together with the trigger population thresholds for a transit technology investment and for shifting from a transit technology to another. The comparative static analyses of the urban system and the trigger threshold for a transit technology investment were also carried out. The transit project investment decisions with and without urban spatial equilibrium consideration were compared. The loss in the project value caused by bias in the NPV approach was also estimated.

The proposed model offers some new insights and important findings. First, transit technology investment can change urban residential distribution and housing market and induce urban sprawl, thus leading to a decentralized city. Ignoring the effects of transit technology investment on land use or urban spatial structure could underestimate the investment return, thus resulting in a late investment of the transit technology. Second, there is a significant difference in the relationships among the investment benefit curves of different transit technologies estimated by the NPV and RO valuation approaches. For the NPV model, there is a trigger population threshold for shifting from a transit technology to another. However, for the RO model, one transit technology is always dominant over the other transit technology. Compared with the RO approach, the NPV approach underestimates the value of a transit technology investment project, causing a premature investment and thus a loss in the project value. Third, the optimal investment timing for a transit technology project is dependent of the type of transit technologies (e.g., BRT, LRT, or metro), project cost and construction duration, discount rate, urban population size, household income level, and population volatility. The investment decisions for single and multiple transit technologies may be different. The proposed modeling methodology can serve as a useful tool for making decisions about public transportation infrastructure investments and for evaluating the effects of transit project investment decisions and urban development policies on urban systems at a strategic level. We believe that the closed-form solution of the proposed model would be helpful for giving insightful findings in making decision for transit technology investment under different boundary conditions.

Although the proposed model provides useful insights for transit infrastructure investment decisions and policy evaluation, some important extensions below could be made for further studies.

(1) The correlation effect between alternative transit technologies was not explicitly 
considered in the transit technology selection problem. A feasible approach to analyze such effect is to assume that the values of underlying transit technology investment projects are stochastic and evolve over time according to a stochastic process (see e.g., Geltner et al., 1996). For example, we may consider two alternative transit technology investment projects $m_{1}$ and $m_{2}$, with values that follow geometric Brownian motion:

$$
d \Phi_{j}(t)=\eta_{j} \Phi_{j}(t) d t+\sigma_{j} \Phi_{j}(t) d w_{j}(t), \quad j=m_{1}, m_{2}
$$

where $\Phi_{j}(t)$ is the value of investing in transit technology project $j$ at time $t . \eta_{j}$ and $\sigma_{j}$ are the expected drift rate and the volatility rate of the value of transit investment project $j$, respectively. $w_{j}(t)$ is a standardized Wiener process. The correlation coefficient $\gamma$ of transit investment projects $m_{1}$ and $m_{2}$ satisfies $E\left[d w_{m_{1}} d w_{m_{2}}\right]=\gamma d t$ and $|\gamma| \leq 1$. In line of this vein, we can explore the effect of correlation coefficient on transit technology investment decision-making for further study.

(2) In this paper, the variation of population size is considered as the major source of uncertainty to affect the transit technology investment decisions. Other sources of uncertainty should also be studied, such as various random factors from the supply side (e.g., fluctuation in investment cost and/or interest rate) and demand side (e.g., attitudes of decision-makers, see Gao and Driouchi, 2013). These factors would have certain impacts on the returns or values of public transportation investment projects. It is thus of great importance to incorporate the investment risk due to other sources of uncertainty in the transit technology investment model.

(3) The transit investment problems in this paper are only investigated for a single transit line in a transportation corridor. However, adding a transit line can usually cause re-distribution of traffic flows in a multi-modal transport network. It is, therefore, necessary to develop a network-based real option model to assess the effects of transit line investment with multiple technology options on the interrelated flows in a realistic network. In this regard, the studies of Chow and Regan (2011a,b), and Chow et al. (2011) provided an important basis for developing such a model for investigating the transit investment problems.

(4) It was assumed in the proposed model that the government was the investor of transit projects with an objective of maximizing the expected social welfare. Recently, as investment 
markets have been progressively deregulated in China, private sectors have been allowed to be involved in public infrastructure investment projects in various ways, such as Build-Operate-Transfer and Public-Private-Partnership. The objective of private investors is however to maximize their own net profit ( $\mathrm{Li}$ et al., 2012b). It is thus worthwhile to extend the proposed model to consider the interests of the private and public investors under different transit market regulatory regimes.

\section{Acknowledgments}

The authors would like to thank three anonymous referees for their helpful comments and suggestions on an earlier draft of the paper. The work described in this paper was jointly supported by the National Natural Science Foundation of China (71222107), the National Basic Research Program of China (973 Program) (2012CB725400, 2012CB725406), and the Research Grants Council of the Hong Kong Special Administrative Region, China (Project Nos. PolyU 5181/13E and 17208614).

\section{References}

Allport, R.J., 1981. The costing of bus, light rail transit and metro public transport systems. Traffic Engineering \& Control 22, 633-639.

Alonso, W., 1964. Location and Land Use: Toward a General Theory of Land Rent. Harvard University Press, Cambridge, MA.

Anas, A., 1982. Residential Location Markets and Urban Transportation. Academic Press, New York.

BAOGAO, 2012. Report on Urban Light Rail Transit Project Feasibility Analyses. $<$ http://www.BaoGaoBaoGao.com/DiaoYan/2012-10/chengshiqingguijianshexiangmukexi ngx.html>.

Beckmann, M.J., 1969. On the distribution of urban rent and residential density. Journal of Economic Theory 1, 60-67.

Beckmann, M.J., 1974. Spatial equilibrium in housing market. Journal of Urban Economics 1, 99-107.

Bowes, D.R., Ihlanfeldt, K.R., 2001. Identifying the impacts of rail transit stations on residential property values. Journal of Urban Economics 50, 1-25. 
Bruun, E., 2005. Bus rapid transit and light rail: Comparing operating costs with a parametric cost model. Transportation Research Record 1927, 11-21.

Chen, Y.J., Li, Z.C., Lam, W.H.K., 2015. Modeling transit technology selection in a linear transportation corridor. Journal of Advanced Transportation 49, 48-72.

ChinaBRT, 2014. Information on Bus Rapid Transit in Chinese and Asian Cities. Available at: $<$ http://www.chinabrt.org $>$.

Chow, J.Y.J., Regan, A.C., 2011a. Real option pricing of network design investments. Transportation Science 45, 50-63.

Chow, J.Y.J., Regan, A.C., 2011b. Network-based real option models. Transportation Research Part B 45, 67-74.

Chow, J.Y.J., Regan, A.C., Ranaiefar, F., Arkhipov, D.I., 2011. A network option portfolio management framework for adaptive transportation planning. Transportation Research Part A 45(8), 765-778.

Chu, X., Polzin, S.E., 2000. Timing rules for major transportation investments. Transportation 27, 201-219.

CPSITS, 2011. Analysis of BRT Systems in Some Typical Chinese Cities. $<$ http://www.cpsits.com/bencandy.php?fid=157\&id=4054> .

de Neufville, R., Scholtes, S., 2011. Flexibility in Engineering Design. MIT Press, Cambridge, MA.

Dixit, A., Pindyck, R., 1994. Investment under Uncertainty. Princeton University Press, Princeton.

Friesz, T.L., Mookherjee, R., Yao, T., 2008. Securitizing congestion: The congestion call option. Transportation Research Part B 42, 407-437.

Fujita, M., 1989. Urban Economic Theory. Cambridge University Press, Cambridge.

Galera, A.L.L., Solino, A.S., 2010. A real options approach for the valuation of highway concessions. Transportation Science 44, 416-427.

Gao, Y., Driouchi, T., 2013. Incorporating Knightian uncertainty into real options analysis: Using multiple-priors in the case of rail transit investment. Transportation Research Part B 55, 23-40.

Geltner, D., Riddiough, T., Stojanovic, S., 1996. Insights on the effect of land use choice: The perpetual option on the best of two underlying assets. Journal of Urban Economics 39, 20-50.

Kraus, M., 2006. Monocentric cities. In: Arnott, R.J., McMillan, D.P. (Eds), A Companion to Urban Economics. Blackwell Publishing, Oxford, pp. 96-108. 
Li, Z.C., Chen, Y.J., Wang, Y.D., Lam, W.H.K., Wong, S.C., 2013. Optimal density of radial major roads in a two-dimensional monocentric city with endogenous residential distribution and housing prices. Regional Science and Urban Economics 43, 927-937.

Li, Z.C., Lam, W.H.K., Wong, S.C., Choi, K., 2012a. Modeling the effects of integrated rail and property development on the design of rail line services in a linear monocentric city. Transportation Research Part B 46, 710-728.

Li, Z.C., Lam, W.H.K., Wong, S.C., Sumalee, A., 2012b. Design of a rail transit line for profit maximization in a linear transportation corridor. Transportation Research Part E 48, 50-70.

Liu, Z., Gu, B.N., Sun, S.C., Deng, C.Y., 2015. Statistics and analysis of urban rail transit lines in 2014, China. Urban Rail Transit Research 1, 1-6.

McDonald, J.F., Osuji, C.I., 1995. The effect of anticipated transportation improvement on residential land values. Regional Science and Urban Economics 25, 261-278.

McDonald, R., Siegel, D., 1986. The value of waiting to invest. Quarterly Journal of Economics 101, 707-727.

Mills, E.S., 1972. Urban Economics. Scott Foresman, Glenview, IL.

NBSC (National Bureau of Statistics of China), 1994-2014. China Statistical Yearbook (1994-2014). China Statistics Press, Beijing, China.

O’Sullivan, A., 2000. Urban Economics. Irwin/McGraw-Hill, Boston.

Parajuli, P.M., Wirasinghe, S.C., 2001. A line haul transit technology selection model. Transportation Planning and Technology 24, 271-308.

Pichayapan, P., Hino, S., Kishi, K., Satoh, K., 2003. Real option analysis in evaluation of expressway projects under uncertainties. Journal of the Eastern Asia Society for Transportation Studies 5, 3015-3030.

Quigley, J.M., 1984. The production of housing services and the derived demand for residential energy. RAND Journal of Economics 15, 555-567.

Saez, D., Cortes, C.E., Milla, F., Nunez, A., Tirachini, A., Riquelme, M., 2012. Hybrid predictive control strategy for a public transport system with uncertain demand. Transportmetrica 8, 61-86.

Saphores, J.D.M., Boarnet, M.G., 2006. Uncertainty and the timing of an urban congestion relief investment: The no-land case. Journal of Urban Economics 59, 189-208.

Sivakumaran, K., Li, Y., Cassidy, M., Madanat, S., 2014. Access and the choice of transit technology. Transportation Research Part A 59, 204-221.

Snell, M., 2011. Cost-benefit Analysis: A Practical Guide. Thomas Telford Limited, London.

Solow, R.M., 1972. Congestion, density and the use of land in transportation. Swedish Journal 
of Economics 74, 161-173.

Solow, R.M., 1973. Congestion cost and the use of land for streets. Bell Journal of Economics Management Science 4, 602-618.

Stutsman, J.M., 2002. Bus rapid transit or light, rail transit: How to decide? Los Angeles case study. Transportation Research Record 1793, 55-61.

Szymanski, S., 1991. The optimal timing of infrastructure investment. Journal of Transport Economics and Policy 12, 247-258.

Tirachini, A., Hensher, D.A., Jara-Diaz, S.R., 2010a. Comparing operator and users costs of light rail, heavy rail and bus rapid transit over a radial public transport network. Research in Transportation Economics 29, 231-242.

Tirachini, A., Hensher, D.A., Jara-Diaz, S.R., 2010b. Restating modal investment priority with an improved model for public transport analysis. Transportation Research Part E 46, 1148-1168.

Trigeorgis, L., 1996. Real Options: Managerial Flexibility and Strategy in Resource Allocation. The MIT Press, Cambridge, MA.

Zhao, T., Sundararajan, S.K., Tseng, C.L., 2004. Highway development decision-making under uncertainty: A real options approach. Journal of Infrastructure Systems 10, 23-32.

Zhao, T., Tseng, C.L., 2003. Valuing flexibility in infrastructure expansion. Journal of Infrastructure Systems 9, 89-97. 


\section{Appendix A: Proof of Proposition 1}

Substituting Eq. (15) into Eq. (18), we obtain

$$
\begin{aligned}
N & =\int_{0}^{B_{i}} n_{i}(x) d x \\
& =\frac{1}{\beta Y_{i}}\left(p_{i}(0) \mu\right)^{1 /(1-\theta)}\left(\theta k^{-1}\right)^{\theta /(1-\theta)} \int_{0}^{B_{i}}\left(1-\frac{\varphi_{i}(x)}{Y_{i}}\right)^{(\alpha+\beta \theta) /(\beta-\beta \theta)} d x \\
& =\left(p_{i}(0) \mu\right)^{1 /(1-\theta)}\left(\theta k^{-1}\right)^{\theta /(1-\theta)}\left(-\frac{V_{i}}{2 \rho \tau}\right)(1-\theta)\left(\left(1-\frac{2 \rho}{Y_{i}}\left(\frac{\tau B_{i}}{V_{i}}+f_{i}\right)\right)^{1 /(\beta-\beta \theta)}-\left(1-\frac{2 \rho f_{i}}{Y_{i}}\right)^{1 /(\beta-\beta \theta)}\right) .
\end{aligned}
$$

Combining Eqs. (17) and (19) yields

$$
R_{A}=(1-\theta) \theta^{\theta /(1-\theta)}\left(\mu p_{i}(0)\left(1-\frac{\varphi_{i}\left(B_{i}\right)}{Y_{i}}\right)^{1 / \beta} k^{-\theta}\right)^{1 /(1-\theta)}
$$

From Eqs. (4) and (5), we have

$$
\varphi_{i}\left(B_{i}\right)=2 \rho\left(\frac{\tau B_{i}}{V_{i}}+f_{i}\right), \quad \forall i=0,1,2 .
$$

Substituting Eq. (A.3) into (A.2), we obtain

$$
p_{i}(0)=\mu^{-1}\left(\frac{k}{\theta}\right)^{\theta}\left(\frac{R_{A}}{1-\theta}\right)^{1-\theta}\left(1-\frac{2 \rho}{Y_{i}}\left(\frac{\tau B_{i}}{V_{i}}+f_{i}\right)\right)^{-1 / \beta}, \forall i=0,1,2
$$

Substituting Eq. (A.4) into (A.1), we obtain

$$
B_{i}=\frac{v_{i}}{\tau}\left(\frac{Y_{i}}{2 \rho}-f_{i}\right)\left(1-\left(\frac{2 N \rho \tau}{R_{A} V_{i}}+1\right)^{\beta(\theta-1)}\right), \quad \forall i=0,1,2
$$

Substituting Eq. (A.5) into (A.4), we have

$$
p_{i}(0)=\mu^{-1}\left(\frac{k}{\theta}\right)^{\theta}\left(\frac{R_{A}}{1-\theta}\right)^{1-\theta}\left(1-\frac{2 \rho f_{i}}{Y_{i}}\right)^{-1 / \beta}\left(\frac{2 N \rho \tau}{R_{A} V_{i}}+1\right)^{(1-\theta)}, \forall i=0,1,2
$$

This completes the proof of Proposition 1. 


\section{Appendix B: Proof of Proposition 2}

The partial derivatives of $p_{i}(0)$ and $B_{i}$ with regard to $Y_{i}, N, V_{i}$, and $f_{i}$ are, respectively, as follows:

$$
\begin{aligned}
& \frac{\partial p_{i}(0)}{\partial Y_{i}}=-\frac{2 \rho f_{i}}{\beta \mu Y_{i}^{2}}\left(\frac{k}{\theta}\right)^{\theta}\left(\frac{R_{A}}{1-\theta}\right)^{1-\theta}\left(\frac{2 N \rho \tau}{R_{A} V_{i}}+1\right)^{(1-\theta)}\left(1-\frac{2 \rho f_{i}}{Y_{i}}\right)^{-(1 / \beta+1)}, \\
& \frac{\partial p_{i}(0)}{\partial N}=\frac{2 \rho \tau}{\mu R_{A} V_{i}}(1-\theta)\left(\frac{k}{\theta}\right)^{\theta}\left(\frac{R_{A}}{1-\theta}\right)^{1-\theta}\left(1-\frac{2 \rho f_{i}}{Y_{i}}\right)^{-1 / \beta}\left(\frac{2 N \rho \tau}{R_{A} V_{i}}+1\right)^{-\theta}, \\
& \frac{\partial p_{i}(0)}{\partial V_{i}}=-\frac{2 N \rho \tau}{\mu R_{A} V_{i}^{2}}(1-\theta)\left(\frac{k}{\theta}\right)^{\theta}\left(\frac{R_{A}}{1-\theta}\right)^{1-\theta}\left(1-\frac{2 \rho f_{i}}{Y_{i}}\right)^{-1 / \beta}\left(\frac{2 N \rho \tau}{R_{A} V_{i}}+1\right)^{-\theta}, \\
& \frac{\partial p_{i}(0)}{\partial f_{i}}=\frac{2 \rho}{\beta \mu Y_{i}}\left(\frac{k}{\theta}\right)^{\theta}\left(\frac{R_{A}}{1-\theta}\right)^{1-\theta}\left(1-\frac{2 \rho f_{i}}{Y_{i}}\right)^{-(1 / \beta+1)}\left(\frac{2 N \rho \tau}{R_{A} V_{i}}+1\right)^{(1-\theta)}, \\
& \frac{\partial B_{i}}{\partial Y_{i}}=\frac{1}{2 \rho} \frac{V_{i}}{\tau}\left(1-\left(\frac{2 N \rho \tau}{R_{A} V_{i}}+1\right)^{\beta(\theta-1)}\right), \\
& \frac{\partial B_{i}}{\partial N}=\beta(1-\theta) \frac{2 \rho \tau}{R_{A} V_{i}} \frac{V_{i}}{\tau}\left(\frac{Y_{i}}{2 \rho}-f_{i}\right)\left(\frac{2 N \rho \tau}{R_{A} V_{i}}+1\right)^{\beta(\theta-1)-1}, \\
& \left.\frac{\partial B_{i}}{\partial V_{i}}=\frac{1}{\tau}\left(\frac{Y_{i}}{2 \rho}-f_{i}\right)\left(1-\left(\frac{2 N \rho \tau}{R_{A} V_{i}}+1\right) f_{i}^{\beta(\theta-1)}\right)+\beta(\theta-1) \frac{2 N \rho \tau}{R_{A} V_{i}^{2}} \frac{V_{i}}{\tau}\left(\frac{Y_{i}}{2 \rho}-f_{i}\right)\left(\frac{2 N \rho \tau}{R_{A} V_{i}}+1\right)\right)^{\beta(\theta-1)-1},
\end{aligned}
$$

As $0<\theta<1$ and $0<\beta<1$ hold, we immediately obtain

$\frac{\partial p_{i}(0)}{\partial Y_{i}}<0, \frac{\partial p_{i}(0)}{\partial N}>0, \frac{\partial p_{i}(0)}{\partial V_{i}}<0, \frac{\partial p_{i}(0)}{\partial f_{i}}>0$.

In addition, under the assumption of $R_{A} V_{2} \square 2 N \rho \tau$, we have

$$
\frac{\partial B_{i}}{\partial Y_{i}}>0, \frac{\partial B_{i}}{\partial N}>0, \frac{\partial B_{i}}{\partial V_{i}}>0, \frac{\partial B_{i}}{\partial f_{i}}<0
$$

This completes the proof of Proposition 2. 


\section{Appendix C: Proof of Proposition 3}

We first derive the expressions for $U_{1}(\cdot)-U_{0}(\cdot)$ and $U_{2}(\cdot)-U_{1}(\cdot)$. According to Eqs. (9) and (20), we have

$$
\begin{aligned}
U_{1}(\cdot)-U_{0}(\cdot) & =\alpha \ln \left(\alpha Y_{1}\right)+\beta \ln \left(\frac{\beta Y_{1}}{p_{1}(0)}\right)-\alpha \ln \left(\alpha Y_{0}\right)+\beta \ln \left(\frac{\beta Y_{1}}{p_{0}(0)}\right) \\
& =\alpha \ln \left(\frac{Y_{1}}{Y_{0}}\right)+\beta \ln \left(\frac{Y_{1}\left(1-\frac{2 \rho f_{0}}{Y_{0}}\right)^{-1 / \beta}\left(\frac{2 N(t) \rho \tau}{R_{A} V_{0}}+1\right)^{1-\theta}}{Y_{0}\left(1-\frac{2 \rho f_{1}}{Y_{1}}\right)^{-1 / \beta}\left(\frac{2 N(t) \rho \tau}{R_{A} V_{1}}+1\right)^{1-\theta}}\right) .
\end{aligned}
$$

Suppose that the household's income level is unchanged over time, i.e., $Y_{0}=Y_{1}=Y_{2}$. Note that $f_{0}=0$ and $f_{1}=0$ hold because the transit project is not yet in operation. Substituting them into Eq. (C.1), we obtain

$$
U_{1}(\cdot)-U_{0}(\cdot)=\beta(1-\theta) \ln \frac{\left(2 N(t) \rho \tau+R_{A} V_{o}\right) V_{1}}{\left(2 N(t) \rho \tau+R_{A} V_{1}\right) V_{0}} .
$$

Similarly, $U_{2}(\cdot)-U_{1}(\cdot)$ can be given by

$$
\begin{aligned}
U_{2}(\cdot)-U_{1}(\cdot) & =\beta \ln \left(\frac{p_{1}(0)}{p_{2}(0)}\right)=\beta \ln \left(\left(1-\frac{2 \rho f_{2}}{Y_{2}}\right)^{1 / \beta}\left(\frac{\left(2 N(t) \rho \tau+R_{A} V_{1}\right) V_{2}}{\left(2 N(t) \rho \tau+R_{A} V_{2}\right) V_{1}}\right)^{1-\theta}\right) \\
& =\beta(1-\theta) \ln \frac{\left(2 N(t) \rho \tau+R_{A} V_{1}\right) V_{2}}{\left(2 N(t) \rho \tau+R_{A} V_{2}\right) V_{1}}+\ln \left(1-\frac{2 \rho f_{2}}{Y_{2}}\right) .
\end{aligned}
$$

When $R_{A} V_{2} \square 2 N \rho \tau$ holds, Eqs. (C.2) and (C.3) can, respectively, be expressed as

$$
\begin{aligned}
& U_{1}(\cdot)-U_{0}(\cdot) \approx \beta(1-\theta) \ln \left(\frac{V_{1}}{V_{0}}\right), \text { and } \\
& U_{2}(\cdot)-U_{1}(\cdot) \approx \beta(1-\theta) \ln \left(\frac{V_{2}}{V_{1}}\right)+\ln \left(1-\frac{2 \rho f_{2}}{Y_{2}}\right) .
\end{aligned}
$$

Substituting Eqs. (C.4) and (C.5) into Eq. (32) yields

$$
\Phi(\cdot)=E\left[\int_{0}^{+\infty} \xi \beta(1-\theta) \ln \left(\frac{V_{1}}{V_{0}}\right) N(t) e^{-k t} d t\right]
$$


$+E\left[\int_{\Delta}^{+\infty}\left(\xi\left(\beta(1-\theta) \ln \left(\frac{V_{2}}{V_{1}}\right)+\ln \left(1-\frac{2 \rho f_{2}}{Y_{2}}\right)\right) N(t)-C_{O}\right) e^{-k t} d t\right]-E\left[\int_{0}^{\Delta} C_{L} e^{-k t} d t\right]$.

As $N(t)$ follows geometric Brownian motion (Dixit and Pindyck, 1994), we have

$$
E\left[N(t) \mid N_{0}=N\right]=N e^{\eta t} .
$$

Substituting Eq. (C.7) into (C.6), we obtain

$$
\begin{aligned}
\Phi(N) & =\xi \beta(1-\theta) \frac{N}{k-\eta} \ln \left(\frac{V_{1}}{V_{0}}\right)+\xi\left[\beta(1-\theta) \ln \left(\frac{V_{2}}{V_{1}}\right)+\ln \left(1-\frac{2 \rho f_{2}}{Y_{2}}\right)\right] \frac{N e^{(\eta-k) \Delta}}{k-\eta} \\
& -\frac{C_{L}\left(1-e^{-k \Delta}\right)}{k}-\frac{C_{O} e^{-k \Delta}}{k} .
\end{aligned}
$$

This completes the proof of Proposition 3. 


\section{Appendix D: Proof of Proposition 4}

By Ito's lemma, we can obtain the solution of Eq. (34) as below

$$
F(N(t))=a_{1}(N(t))^{b_{1}}
$$

where $b_{1}=\frac{1}{2}-\frac{\eta}{\sigma^{2}}+\sqrt{\left(\frac{\eta}{\sigma^{2}}-\frac{1}{2}\right)^{2}+\frac{2 k}{\sigma^{2}}}>1$ and $a_{1}$ is a positive constant to be determined.

From the value-matching condition in Eq. (31) as well as Eqs. (D.1) and (33), we obtain

$$
\begin{aligned}
a_{1}\left(N^{*}\right)^{b_{1}} & =\xi \beta(1-\theta) \frac{N^{*}}{k-\eta} \ln \left(\frac{V_{1}}{V_{0}}\right)+\xi\left(\beta(1-\theta) \ln \left(\frac{V_{2}}{V_{1}}\right)+\ln \left(1-\frac{2 \rho f_{2}}{Y_{2}}\right)\right) \frac{N^{*} e^{(\eta-k) \Delta}}{k-\eta} \\
& -\frac{C_{L}\left(1-e^{-k \Delta}\right)}{k}-\frac{C_{O} e^{-k \Delta}}{k} .
\end{aligned}
$$

By the smooth-pasting condition (see Dixit and Pindyck, 1994), we have

$$
\left.\frac{d F(N)}{d N}\right|_{N=N^{*}}=\left.\frac{d \Phi(N)}{d N}\right|_{N=N^{*}} .
$$

Eq. (D.3) can be written as

$$
\begin{aligned}
a_{1} b_{1}\left(N^{*}\right)^{b_{1}-1}= & \xi \beta(1-\theta) \frac{1}{k-\eta} \ln \left(\frac{V_{1}}{V_{0}}\right)+\xi\left(\beta(1-\theta) \ln \left(\frac{V_{2}}{V_{1}}\right)+\ln \left(1-\frac{2 \rho f_{2}}{Y_{2}}\right)\right) \frac{e^{(\eta-k) \Delta}}{k-\eta} \\
& -\left.\frac{\left(1-e^{-k \Delta}\right)}{k} \frac{d C_{L}}{d N}\right|_{N=N^{*}}-\left.\frac{e^{-k \Delta}}{k} \frac{d C_{O}}{d N}\right|_{N=N^{*}},
\end{aligned}
$$

where

$$
\begin{aligned}
& \left.\frac{d C_{L}}{d N}\right|_{N=N^{*}}=\beta(1-\theta) \lambda_{1} \frac{2 \rho}{R_{A}}\left(\frac{Y_{2}}{2 \rho}-f_{2}\right)\left(\frac{2 N^{*} \rho \tau}{R_{A} V_{2}}+1\right)^{\beta(\theta-1)-1}, \text { and } \\
& \left.\frac{d C_{O}}{d N}\right|_{N=N^{*}}=\beta(1-\theta) \frac{4 \rho \omega_{1}}{V_{2} H R_{A}}\left(\frac{Y_{2}}{2 \rho}-f_{2}\right)\left(\frac{2 N^{*} \rho \tau}{R_{A} V_{2}}+1\right)^{\beta(\theta-1)-1} .
\end{aligned}
$$

When $R_{A} V_{2} \square 2 N \rho \tau$ holds, the right-hand sides of Eqs. (D.5) and (D.6) approximate to zero. The final two terms of Eq. (D.4) then disappear. Solving the system of Eqs. (D.2) and (D.4), one obtains expression (35) for the population threshold $N^{*}$. Then, one can further determine the parameter $a_{1}$ by Eq. (D.4), and thus expression (36) for the option value $F(N(t))$ according to Eq. (D.1). This completes the proof of this proposition. 


\section{Appendix E: Proof of Proposition 5}

For ease of presentation, we denote

$$
\zeta_{1}=\beta(1-\theta) \ln \left(\frac{V_{1}}{V_{0}}\right), \text { and } \zeta_{2}=\beta(1-\theta) \ln \left(\frac{V_{2}}{V_{1}}\right)+\ln \left(1-\frac{2 \rho f_{2}}{Y_{2}}\right)
$$

The partial derivatives of $N^{*}$ with regard to $\sigma, \lambda_{1}, \omega_{1}$, and $\Delta$ are then given as follows:

$$
\begin{aligned}
& \frac{\partial N^{*}}{\partial \sigma}=\frac{2 \sigma b_{1}(k-\eta)\left[C_{L}\left(1-e^{-k \Delta}\right)+C_{O} e^{-k \Delta}\right]}{\xi k\left(b_{1}-1\right)\left(\sigma^{2}\left(2 b_{1}-1\right)+2 \eta\right)\left(\zeta_{1}+\zeta_{2} e^{(\eta-k) \Delta}\right)}, \\
& \frac{\partial N^{*}}{\partial \lambda_{1}}=\frac{b_{1} V_{2}(k-\eta)\left(Y_{2}-2 \rho f_{2}\right)\left(1-e^{-k \Delta}\right)}{2 \xi k \rho \tau\left(b_{1}-1\right)\left(\zeta_{1}+\zeta_{2} e^{(\eta-k) \Delta}\right)}, \\
& \frac{\partial N^{*}}{\partial \omega_{1}}=\frac{b_{1}(k-\eta)\left(Y_{2}-2 \rho f_{2}\right) e^{-k \Delta}}{\xi k \rho \tau H\left(b_{1}-1\right)\left(\zeta_{1}+\zeta_{2} e^{(\eta-k) \Delta}\right)}, \\
& \frac{\partial N^{*}}{\partial \Delta}=\frac{b_{1}(k-\eta)\left(C_{L}-C_{O}\right) e^{-k \Delta}+N^{*} \xi\left(b_{1}-1\right)(k-\eta) \zeta_{2} e^{(\eta-k) \Delta}}{\xi\left(b_{1}-1\right)\left(\zeta_{1}+\zeta_{2} e^{(\eta-k) \Delta}\right)} .
\end{aligned}
$$

Note that $0<\theta<1, b_{1}>1, Y_{2}>2 \rho f_{2}$, and $k>\eta$ hold. We thus obtain

$$
\frac{\partial N^{*}}{\partial \sigma}>0, \frac{\partial N^{*}}{\partial \lambda_{1}}>0, \text { and } \frac{\partial N^{*}}{\partial \omega_{1}}>0
$$

The sign of $\frac{\partial N^{*}}{\partial \Delta}$ depends on the sign of $C_{L}-C_{O}$. As $C_{L} \geq C_{O}$, we have

$$
\frac{\partial N^{*}}{\partial \Delta}>0
$$

However, when $C_{L}<C_{O}$, the sign of $\frac{\partial N^{*}}{\partial \Delta}$ is ambiguous. This completes the proof of Proposition 5. 
Table 1 Applications of real option theory to transportation infrastructure investment issues.

\begin{tabular}{|c|c|c|c|c|c|c|}
\hline Citation & $\begin{array}{l}\text { Type of } \\
\text { transportation } \\
\text { infrastructure }\end{array}$ & Decision variables & Objective function & $\begin{array}{l}\text { Considering effects } \\
\text { of investment on } \\
\text { land use or urban } \\
\text { spatial structure } \\
\end{array}$ & Model solution & Source of uncertainty \\
\hline $\begin{array}{l}\text { Pichayapan et al. } \\
\text { (2003) }\end{array}$ & Expressway & $\begin{array}{c}\text { Immediate } \\
\text { investment or defer } \\
\text { to invest }\end{array}$ & $\begin{array}{l}\text { Max. expected net } \\
\text { project benefit with } \\
\text { binomial method }\end{array}$ & No & Simulation & Traffic volume \\
\hline Zhao et al. (2004) & A highway corridor & $\begin{array}{l}\text { Number of lanes, } \\
\text { right-of-way width, } \\
\text { rehabilitation or not }\end{array}$ & Max. expected profit & No & Simulation & $\begin{array}{c}\text { Traffic demand, land } \\
\text { price, and highway } \\
\text { deterioration level }\end{array}$ \\
\hline $\begin{array}{l}\text { Saphores and } \\
\text { Boarnet (2006) }\end{array}$ & $\begin{array}{l}\text { A highway corridor } \\
\text { or a transit line }\end{array}$ & Investment timing & $\begin{array}{l}\text { Max. expected utility } \\
\text { changes of residents } \\
\text { before and after } \\
\text { investment }\end{array}$ & No & Closed-form & Urban population \\
\hline Friesz et al. (2008) & $\begin{array}{l}\text { Transportation } \\
\text { network }\end{array}$ & $\begin{array}{l}\text { Flow distribution } \\
\text { over time and space }\end{array}$ & $\begin{array}{l}\text { Max. expected net } \\
\text { trip value }\end{array}$ & No & Simulation & Trip (or asset) cost \\
\hline $\begin{array}{l}\text { Galera and Solino } \\
(2010)\end{array}$ & A highway corridor & Highway concession & $\begin{array}{l}\text { Max. expected cash } \\
\text { flows or revenue } \\
\text { Max. option value }\end{array}$ & No & Closed-form & Traffic volume \\
\hline $\begin{array}{c}\text { Chow and Regan } \\
\text { (2011a) }\end{array}$ & $\begin{array}{l}\text { Transportation } \\
\text { network }\end{array}$ & $\begin{array}{l}\text { Link improvement } \\
\text { timing }\end{array}$ & $\begin{array}{c}\text { (including options to } \\
\text { defer and re-design } \\
\text { network) }\end{array}$ & No & Simulation & Travel demand \\
\hline $\begin{array}{c}\text { Chow and Regan } \\
\text { (2011b) }\end{array}$ & $\begin{array}{l}\text { Transportation } \\
\text { network }\end{array}$ & $\begin{array}{l}\text { Link improvement } \\
\text { timing and capacity } \\
\text { expansions }\end{array}$ & $\begin{array}{l}\text { Max. option value } \\
\text { (including options to } \\
\text { defer and re-order } \\
\text { project) }\end{array}$ & No & Simulation & Travel demand \\
\hline $\begin{array}{l}\text { Gao and Driouchi } \\
\text { (2013) }\end{array}$ & A rail transit line & Investment timing & $\begin{array}{l}\text { Alpha-maxmin. } \\
\text { expected utility } \\
\text { changes of residents } \\
\text { before and after } \\
\text { investment }\end{array}$ & No & Closed-form & $\begin{array}{c}\text { Urban population } \\
\text { and decision-making } \\
\text { uncertainty }\end{array}$ \\
\hline This paper & A transit line & $\begin{array}{l}\text { Transit technology } \\
\text { selection and } \\
\text { investment timing }\end{array}$ & $\begin{array}{l}\text { Max. expected social } \\
\text { welfare }\end{array}$ & Yes & Closed-form & Urban population \\
\hline
\end{tabular}


Table 2 Basic model assumptions.

\begin{tabular}{|c|c|}
\hline $\begin{array}{c}\text { No. of } \\
\text { assumntion }\end{array}$ & Description \\
\hline A1 & $\begin{array}{l}\text { We assume that the authority or government is the investor of transit project, and makes } \\
\text { transit investment decisions in a sequential way. Specifically, it first decides which transit } \\
\text { technology to choose, and then when to invest. The time horizon considered in this paper is } \\
\text { infinite. The objective of transit technology investment is to maximize the expected social } \\
\text { welfare of the urban system over the infinite time horizon. We also assume that the interest } \\
\text { rate is riskless and is a known constant over the time horizon. In China, the current interest } \\
\text { rate is around } 6 \% \text {. However, in other countries, it may range from } 9 \% \text { to } 15 \% \text { for } \\
\text { infrastructure investment projects. }\end{array}$ \\
\hline A2 & $\begin{array}{l}\text { The city studied is assumed to be linear, closed, and monocentric, implying that all job } \\
\text { opportunities are located in the urban central business district (CBD). The value of land at } \\
\text { or beyond the city boundary is equal to the agricultural rent or opportunity cost of the land. } \\
\text { These assumptions have been widely adopted in the field of urban economics (see, for } \\
\text { example, Alonso, 1964; Mills, 1972; Fujita, 1989; O'Sullivan, 2000; Kraus, 2006; Li et al., } \\
\text { 2013). }\end{array}$ \\
\hline A3 & $\begin{array}{l}\text { The housing market contains the authority, property developer, and household agents. The } \\
\text { authority aims to choose a transit technology and the investment timing to maximize the } \\
\text { (expected) investment return or value of the transit project in terms of the expected social } \\
\text { welfare. The property developers determine the intensity of their capital investment in the } \\
\text { land market to maximize the net profit generated by the supply of housing. Each property } \\
\text { developer is assumed to adopt a Cobb-Douglas housing production function (see, for } \\
\text { example, Beckmann, 1974; Quigley, 1984; Li et al., 2013). }\end{array}$ \\
\hline A4 & $\begin{array}{l}\text { All households in the city are assumed to be homogenous, implying that their income } \\
\text { levels and utility functions are identical. Each household has a Cobb-Douglas utility } \\
\text { function. A household's income is spent on transportation, housing, and composite goods. } \\
\text { The objective of each household is to maximize its utility by choosing a residential } \\
\text { location, housing space size, and amount of other goods within its budget constraints (see, } \\
\text { for example, Solow, 1972, 1973; Beckmann, 1969, 1974; Anas, 1982; Fujita, 1989). It is } \\
\text { further assumed that the urban population size (represented by } N>0 \text { ) stochastically } \\
\text { fluctuates over time and follows a geometric Brownian motion (see also Saphores and } \\
\text { Boarnet, 2006; Gao and Driouchi, 2013). }\end{array}$ \\
\hline A5 & $\begin{array}{l}\text { We assume that the average daily number of trips to the CBD by transit modes per } \\
\text { household is } \delta \text {. For example, } \delta=1 \text { indicates that each household makes an average of } \\
\text { one trip to the CBD by transit modes per day. }\end{array}$ \\
\hline
\end{tabular}


Table 3 The effects of the model parameters on the housing rental price in the CBD area and the city boundary.

\begin{tabular}{c|c|c|c|c}
\hline & $Y_{i}$ & $N$ & $V_{i}$ & $f_{i}$ \\
\hline$p_{i}(0)$ & - & + & - & + \\
$B_{i}$ & + & + & + & - \\
\hline
\end{tabular}

Note: "+" represents a positive correlation and "-" represents a negative correlation.

Table 4 Input parameters for model application.

\begin{tabular}{clc}
\hline Parameter & \multicolumn{1}{c}{ Definition } & $\begin{array}{c}\text { Baseline } \\
\text { value }\end{array}$ \\
\hline$Y$ & Average annual household income (RMB/year) & 80,000 \\
$R_{A}$ & Agricultural rent at the city boundary (RMB/ $\mathrm{km}^{2} /$ year) & 100 \\
$\alpha, \beta$ & Parameters in the household utility function & $0.75,0.25$ \\
$\theta, \mu$ & Parameters in the housing production function & $0.7,0.05$ \\
$V_{0}, V_{1}$ & $\begin{array}{l}\text { Average journey speed before and during project construction } \\
f_{0}, \quad f_{1}\end{array}$ & Fare before and during project construction (RMB) \\
$H$ & Transit service headway (hour/vehicle) & 20,18 \\
$\xi$ & Parameter in the social welfare function & 0,0 \\
$\eta$ & Annual population growth rate & 0.1 \\
$\sigma$ & Population volatility rate & 6350 \\
$k$ & Riskless interest rate & $1.1 \%$ \\
$\delta$ & Average daily number of trips to the CBD area per household & $8.0 \%$ \\
\hline
\end{tabular}

Source: please refer to Li et al. (2012a), Saphores and Boarnet (2006), and Chen et al. (2015). 
Table 5 Input parameters for the metro, LRT, and BRT technologies.

\begin{tabular}{|c|c|c|c|c|}
\hline Parameter & Definition & Metro & LRT & BRT \\
\hline$V_{2}$ & Average vehicle operating speed $(\mathrm{km} / \mathrm{h})$ & 40 & 35 & 30 \\
\hline$f_{2}$ & Transit fare (RMB) & 4.0 & 3.0 & 2.0 \\
\hline$\lambda_{0}$ & $\begin{array}{l}\text { Fixed component of the annual transit facility cost } \\
\text { (million RMB/year) }\end{array}$ & 1.2 & 1.0 & 0.7 \\
\hline$\lambda_{1}$ & $\begin{array}{l}\text { Variable component of the annual transit facility } \\
\text { cost (million } \mathrm{RMB} / \mathrm{km} / \text { year) }\end{array}$ & 50.0 & 7.0 & 5.0 \\
\hline$\omega_{0}$ & $\begin{array}{l}\text { Fixed component of the annual transit operating } \\
\text { cost (million RMB/year) }\end{array}$ & 1.2 & 0.5 & 0.35 \\
\hline$\omega_{1}$ & $\begin{array}{l}\text { Variable component of the annual transit } \\
\text { operating cost (million RMB/vehicle/year) }\end{array}$ & 6.5 & 1.8 & 1.5 \\
\hline$\Delta$ & $\begin{array}{l}\text { Duration of the construction of the transit line } \\
\text { (years) }\end{array}$ & 5 & 3 & 1 \\
\hline
\end{tabular}
Source: CPSITS (2011), BAOGAO (2012), and Li et al. (2012a).

Table 6 Trigger population thresholds (million people) for different transit technology investments for the RO and NPV models with and without land use equilibrium.

\begin{tabular}{cccccc}
\hline \multirow{2}{*}{$\begin{array}{c}\text { Transit } \\
\text { technology }\end{array}$} & Approach & \multicolumn{2}{c}{ With land use equilibrium } & \multicolumn{2}{c}{ Without land use equilibrium } \\
\cline { 3 - 6 } & used & $N^{*}$ & $N^{* *}$ & $N^{*}$ & $N^{* *}$ \\
\hline Metro & RO & 8.20 & 8.20 & 9.50 & 9.50 \\
& NPV & 5.70 & 6.38 & 6.60 & 7.35 \\
LRT & RO & 6.20 & 6.20 & 6.50 & 6.50 \\
& NPV & 4.31 & 4.85 & 4.50 & 4.95 \\
BRT & RO & 4.39 & 4.39 & 4.70 & 4.70 \\
& NPV & 3.05 & 3.05 & 3.20 & 3.20 \\
\hline
\end{tabular}

Note: $N^{*}$ denotes the trigger population threshold for a single transit technology, and is given by Eq. (35). $N^{* *}$ denotes the trigger population threshold for selecting among multiple transit technology options, and is determined by Eq. (46). 
Table 7 Equilibrium solutions of the urban system with different transit technology investments when the urban population size is fixed as 8.2 million people.

\begin{tabular}{lcccc}
\hline Performance index & Metro & LRT & BRT & $\begin{array}{c}\text { Doing } \\
\text { nothing }\end{array}$ \\
\hline $\begin{array}{l}\text { City length }(\mathrm{km}) \\
\text { Average urban residential } \\
\left.\text { density (households } / \mathrm{km}^{2}\right)\end{array}$ & 55.3 & 50.0 & 46.0 & 39.7 \\
$\begin{array}{l}\text { Average housing rental price } \\
\left(\mathrm{RMB} / \mathrm{m}^{2}\right)\end{array}$ & 4550 & 5100 & 5522 & 5642 \\
$\begin{array}{l}\text { Average housing space per } \\
\text { household ( } \mathrm{m}^{2} / \text { household) }\end{array}$ & 39 & 37 & 34 & 29 \\
$\begin{array}{l}\text { Average land value }\left(\mathrm{RMB} / \mathrm{m}^{2}\right) \\
\text { Average capital investment }\end{array}$ & 776 & 840 & 912 & 941 \\
intensity (million $\left.\mathrm{RMB} / \mathrm{km}{ }^{2}\right)$ & 166.9 & 174.1 & 186.2 & 196.2 \\
\hline
\end{tabular}


Table 8 Population sizes and per capita income levels of two candidate cities between 1994 and 2014.

\begin{tabular}{|c|c|c|c|c|}
\hline \multirow{2}{*}{ Year } & \multicolumn{2}{|c|}{ Population size (million people) } & \multicolumn{2}{|c|}{$\begin{array}{l}\text { Per capita income level } \\
\text { (RMB/year/person) }\end{array}$} \\
\hline & Dalian & Changzhou & Dalian & Changzhou \\
\hline 1994 & 5.039 & 3.310 & 3152 & 4123 \\
\hline 1995 & 5.295 & 3.390 & 3574 & 4532 \\
\hline 1996 & 5.350 & 3.510 & 4001 & 4847 \\
\hline 1997 & 5.566 & 3.550 & 4544 & 5322 \\
\hline 1998 & 5.690 & 3.704 & 5077 & 5633 \\
\hline 1999 & 5.770 & 3.770 & 5434 & 6192 \\
\hline 2000 & 5.890 & 3.795 & 6098 & 6392 \\
\hline 2001 & 5.966 & 3.855 & 6234 & 7205 \\
\hline 2002 & 5.984 & 3.902 & 6765 & 7833 \\
\hline 2003 & 5.992 & 3.923 & 7255 & 8705 \\
\hline 2004 & 6.015 & 4.023 & 8183 & 9851 \\
\hline 2005 & 6.020 & 4.110 & 11994 & 11379 \\
\hline 2006 & 6.060 & 4.257 & 13456 & 14356 \\
\hline 2007 & 6.080 & 4.352 & 15456 & 18765 \\
\hline 2008 & 6.130 & 4.407 & 17234 & 24092 \\
\hline 2009 & 6.170 & 4.452 & 19734 & 26723 \\
\hline 2010 & 6.690 & 4.593 & 21923 & 27455 \\
\hline 2011 & 6.740 & 4.650 & 24276 & 29559 \\
\hline 2012 & 6.850 & 4.687 & 27480 & 33587 \\
\hline 2013 & 6.954 & 4.692 & 29434 & 35232 \\
\hline 2014 & 6.966 & 4.723 & 30238 & 39483 \\
\hline $\begin{array}{l}\text { Average annual } \\
\text { growth rate }\end{array}$ & $1.65 \%$ & $1.80 \%$ & $12.27 \%$ & $12.20 \%$ \\
\hline $\begin{array}{l}\text { Population } \\
\text { volatility rate }\end{array}$ & $2.05 \%$ & $1.16 \%$ & - & - \\
\hline
\end{tabular}


Table 9 Estimated investment timings for two candidate cities under population trajectory 1.

\begin{tabular}{cccc}
\hline \multirow{2}{*}{ Transit technology } & Approach used & \multicolumn{2}{c}{ Estimated investment timing (Year) } \\
\cline { 3 - 4 } & & Dalian & Changzhou \\
\hline Metro & RO & 2015 & 2020 \\
& NPV & 2001 & 2005 \\
\multirow{2}{*}{ LRT } & RO & 2007 & 2009 \\
& NPV & 1997 & 2001 \\
BRT & RO & - & 2003 \\
& NPV & - & 1997
\end{tabular}

Note: The population size of Dalian city has exceeded 5.0 million since 1994 (see Table 8 ). A BRT cannot satisfy the needs of the urban development of Dalian city, and thus a BRT project is not considered.

Table 10 Average project value over the simulated population trajectories for each candidate city.

\begin{tabular}{cccc}
\hline \multirow{2}{*}{$\begin{array}{c}\text { Transit } \\
\text { technology }\end{array}$} & Approach used & \multicolumn{2}{c}{ Average project values (billion RMB) } \\
\cline { 3 - 4 } Metro & & Dalian & Changzhou \\
& RO & 151.76 & 192.87 \\
& NPV & 107.13 & 118.67 \\
LRT & Difference & 44.63 & 74.20 \\
& RO & 54.93 & 37.43 \\
& NPV & 35.82 & 25.56 \\
BRT & Difference & 19.11 & 11.87 \\
& RO & - & 15.11 \\
& NPV & - & 10.26 \\
& Difference & - & 4.85 \\
\hline
\end{tabular}


With land use equilibrium

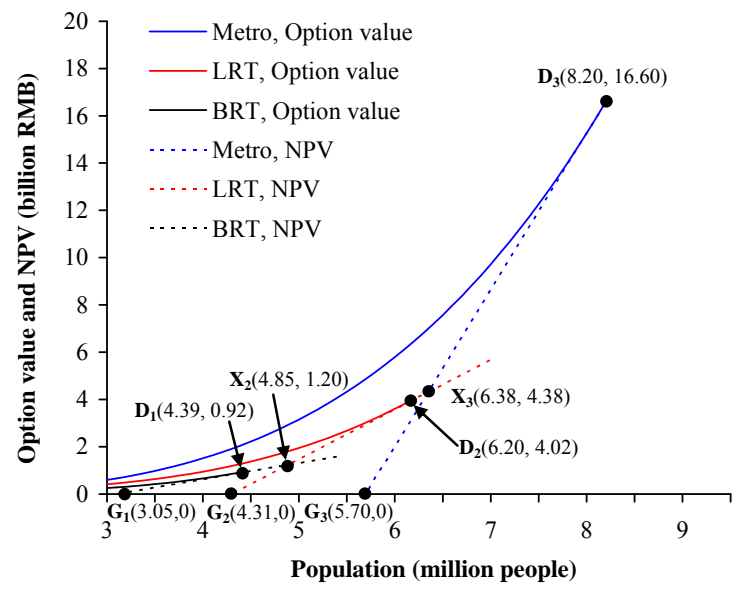

(a)
Without land use equilibrium

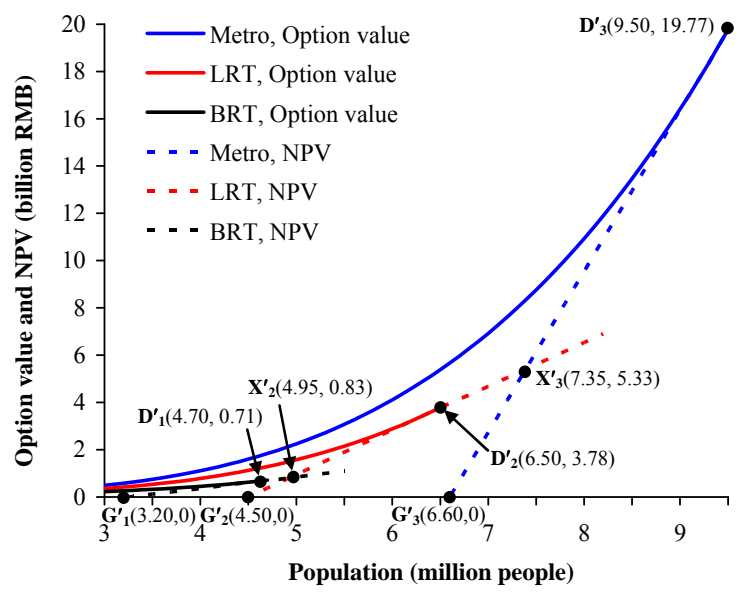

(b)

Fig. 1. Option value curves (in bold line) and NPV curves (in dotted line) under different transit technology investments with and without land use equilibrium consideration. 


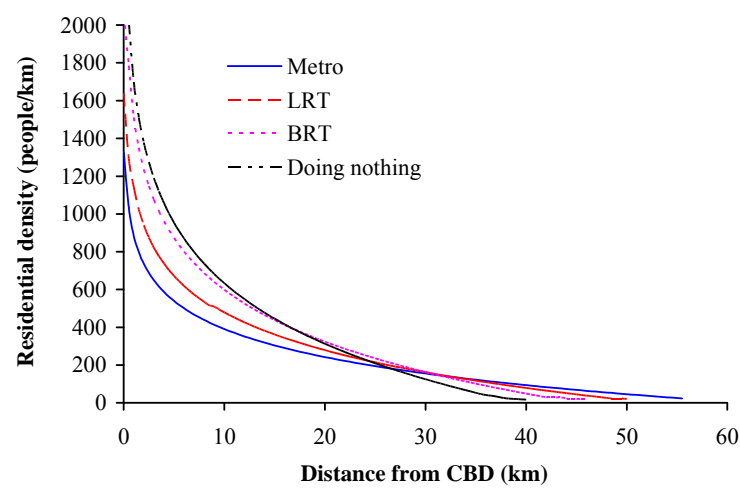

(a)

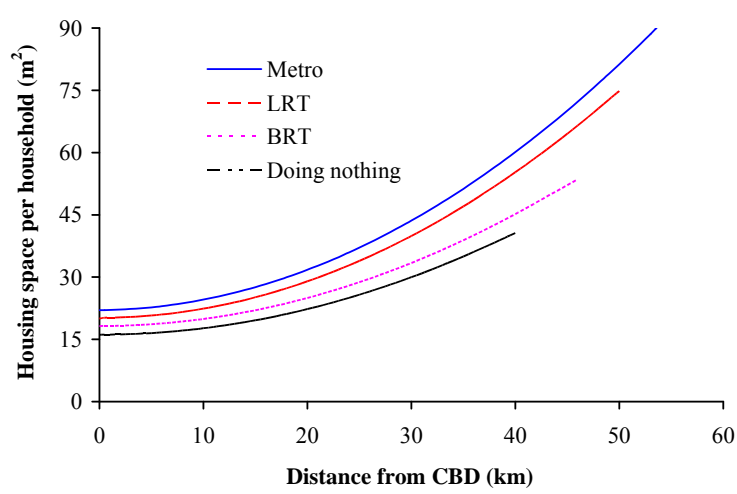

(c)

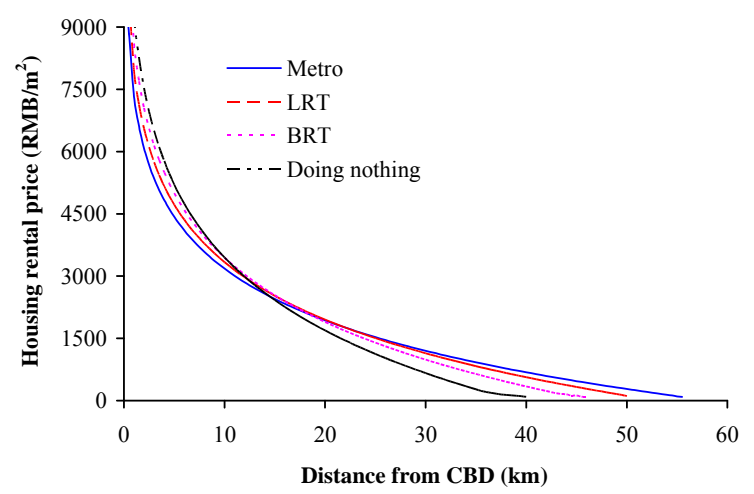

(b)

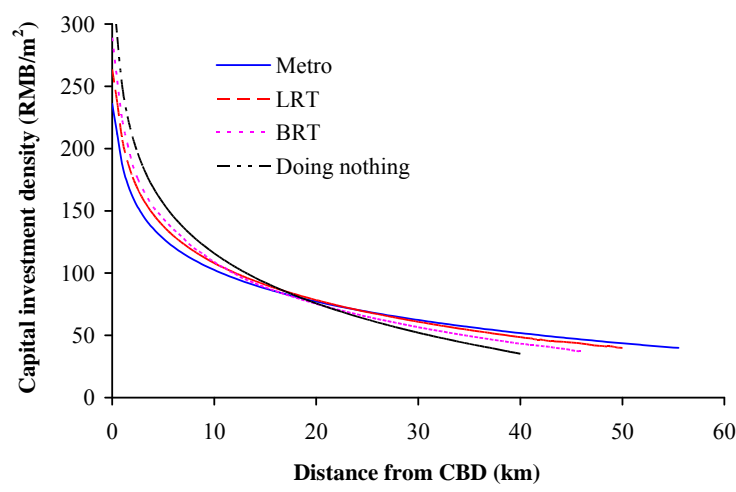

(d)

Fig. 2. (a)-(d) represent household residential density, housing rental price, housing space per household, and capital investment intensity for a given population size of 8.2 million people, respectively. 


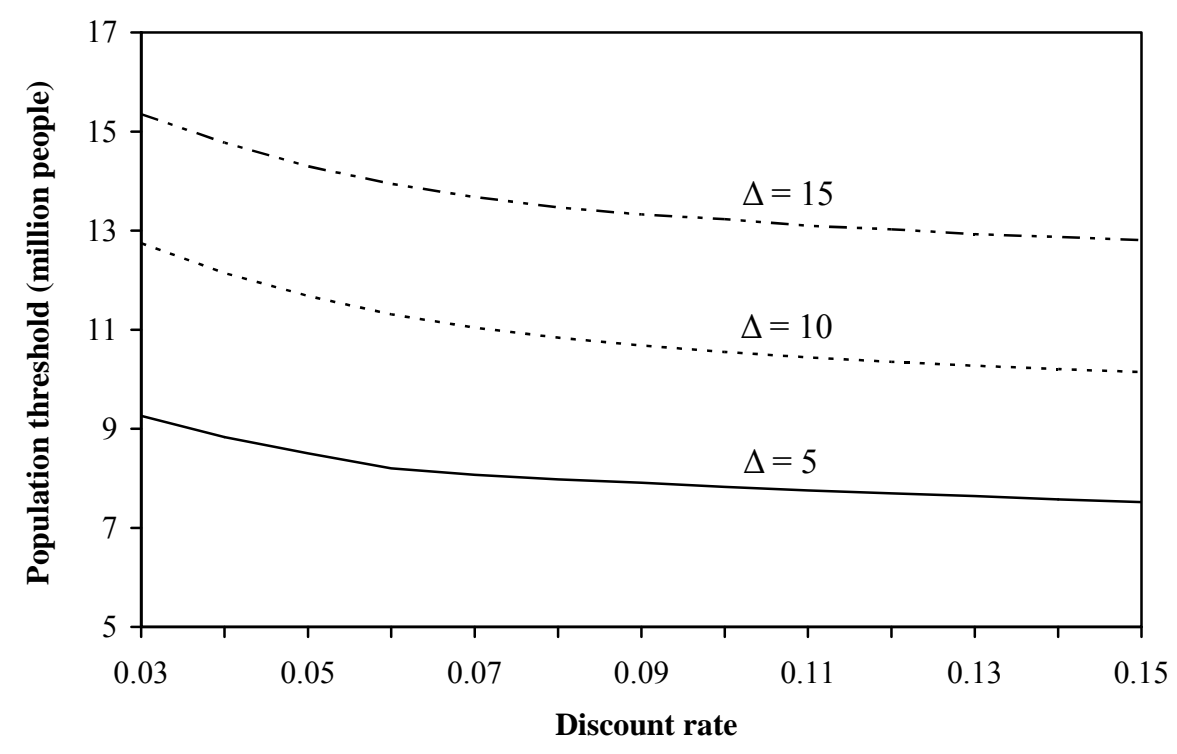

Fig. 3. Change of the population threshold with the discount rate and metro project construction duration.

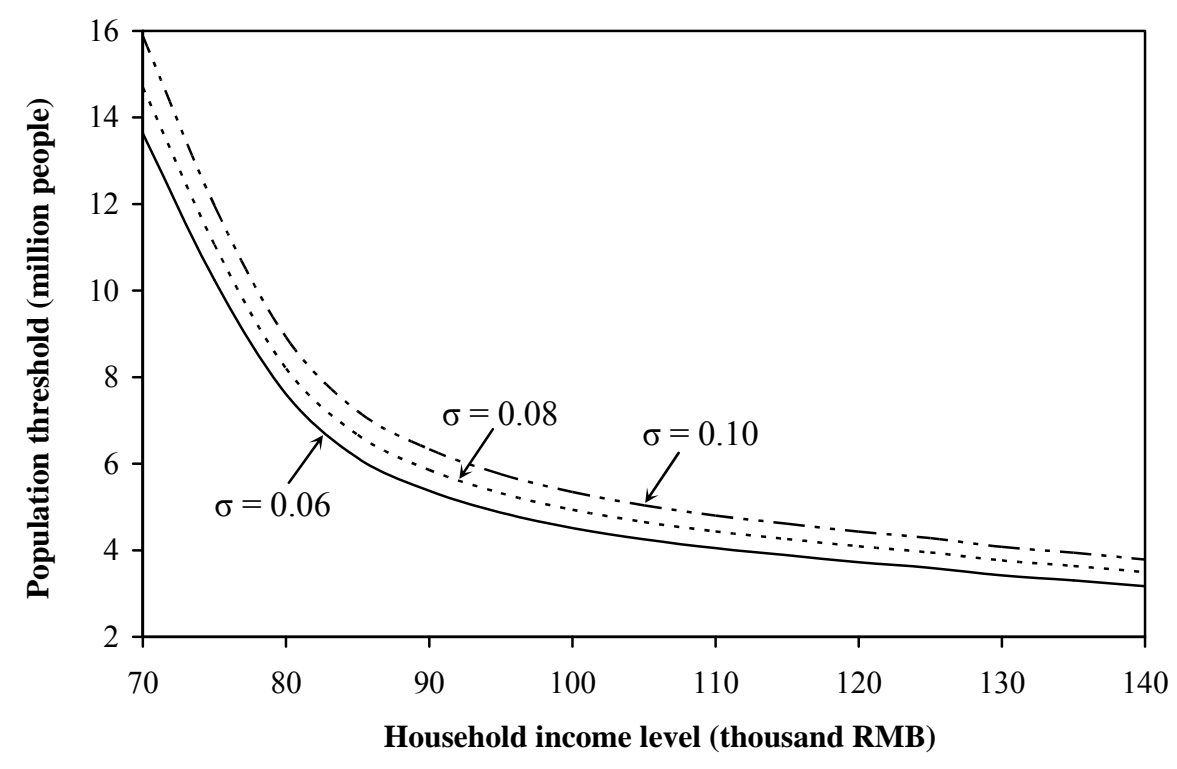

Fig. 4. Change of the population threshold with the household income and population volatility. 


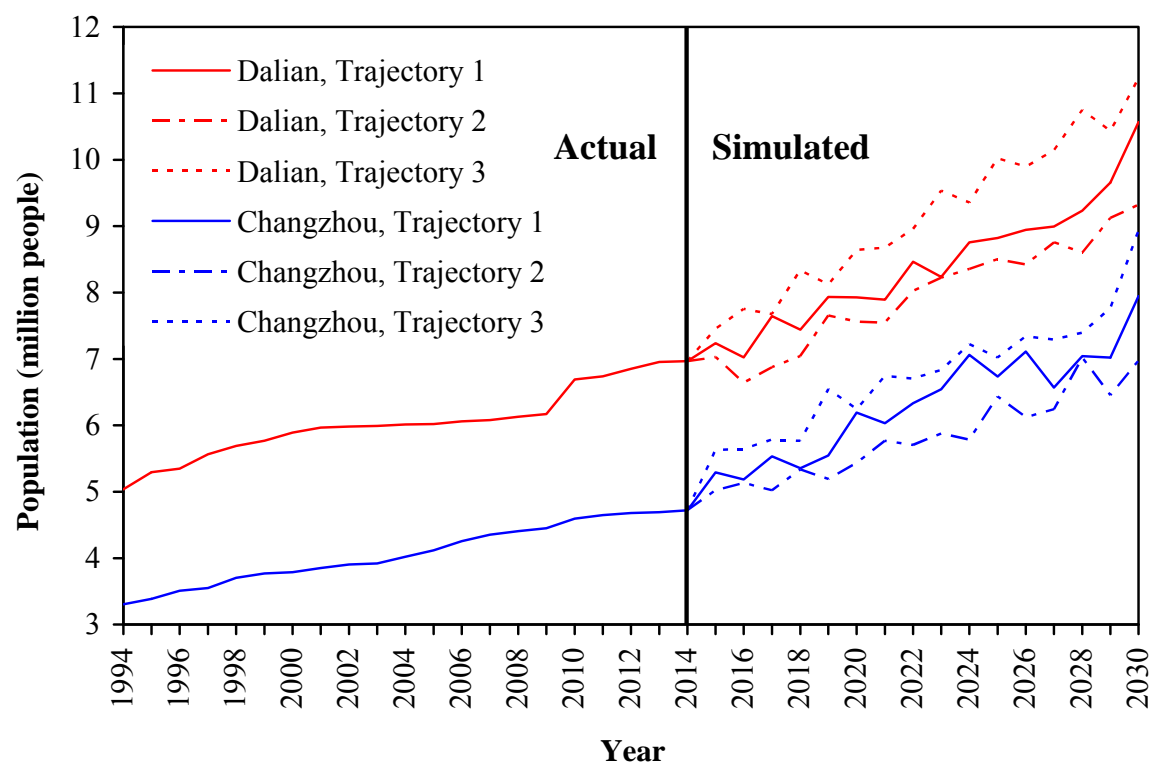

Fig. 5. Actual and simulated population sizes of two candidate cities between 1994 and 2030 . The population size after 2014 is simulated according to geometric Brownian motion.

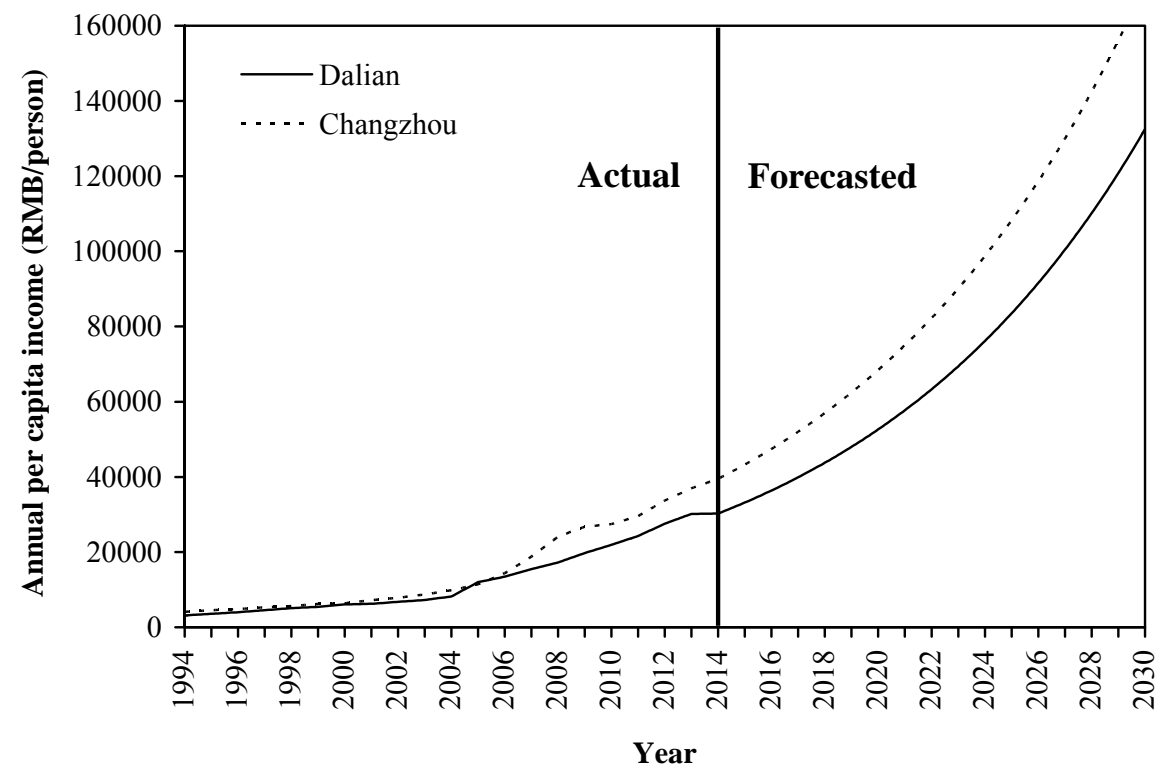

Fig. 6. Actual and forecasted annual per capita income levels of two candidate cities between 1994 and 2030. The per capita income level after 2014 grows by a constant rate. 


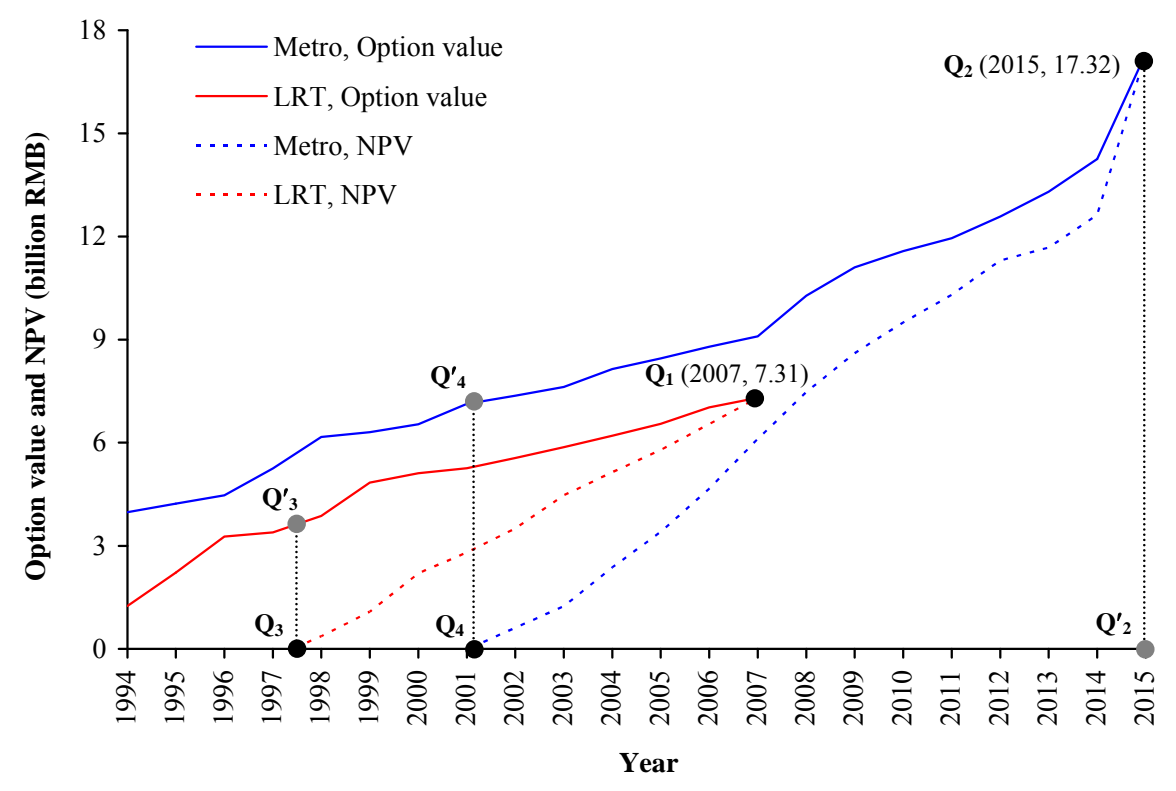

Fig. 7a. Option value and NPV of introducing a metro or LRT in Dalian under simulated population trajectory 1 .

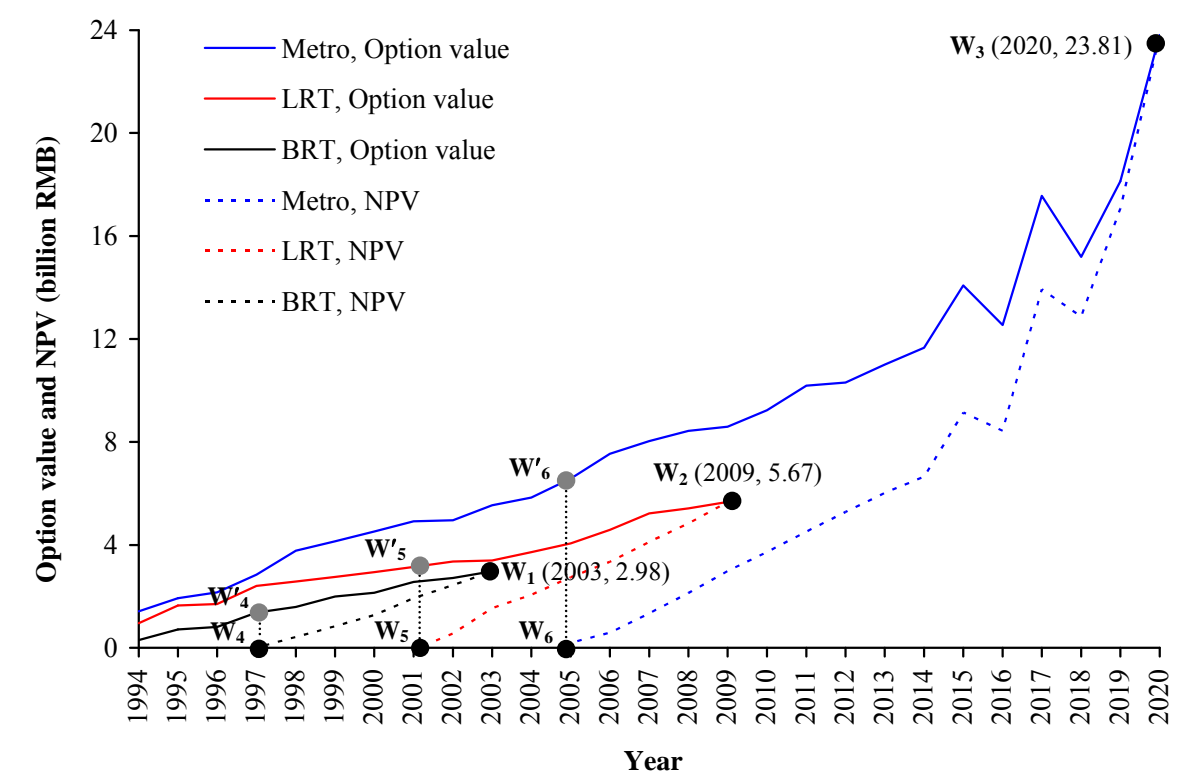

Fig. 7b. Option value and NPV of introducing a metro, LRT, or BRT in Changzhou under simulated population trajectory 1 . 